\title{
PCNA activates the MutL $\gamma$ endonuclease to promote meiotic crossing over
}

Dhananjaya S. Kulkarni ${ }^{1, \dagger}$, Shannon Owens ${ }^{1, \dagger}$, Masayoshi Honda ${ }^{1, \ddagger}$, Masaru Ito $^{1, f}$, Ye Yang ${ }^{2, \S}$, Mary W. Corrigan ${ }^{1}$, Lan Chen ${ }^{1}$, Aric L. Quan ${ }^{1}$ and Neil Hunter ${ }^{1,2,3,{ }^{*}}$

${ }^{1}$ Howard Hughes Medical Institute, University of California, Davis, Davis, California, USA.

${ }^{2}$ Department of Microbiology \& Molecular Genetics, University of California, Davis, Davis, California, USA.

${ }^{3}$ Department of Molecular \& Cellular Biology, University of California, Davis, Davis, California, USA.

${ }^{\dagger}$ D.S.K. and S.O. contributed equally to this work

${ }^{\ddagger}$ Current address: Carver College of Medicine, University of lowa, lowa City, lowa, USA.

${ }^{f}$ Current address: Institute for Protein Research, Osaka University, Osaka, Japan

$\S$ Current address: ScienCell Research Laboratories, Carlsbad, California, USA.

* Correspondence to: Neil Hunter, E-mail: nhunter@ucdavis.edu 


\section{Abstract}

During meiosis, crossover recombination connects homologous chromosomes to direct their accurate segregation ${ }^{1}$. Defects in crossing over cause infertility, miscarriage and congenital disease. Accordingly, each pair of chromosomes attains at least one crossover through processes that designate and then implement crossing over with high efficiency ${ }^{2}$. At the DNA level, crossing over is implemented through the formation and biased resolution of doubleHolliday Junction intermediates ${ }^{3-5}$. A central tenet of crossover resolution is that the two Holliday junctions are resolved in opposite planes by targeting nuclease incisions to specific DNA strands ${ }^{6}$. Although the endonuclease activity of the MutL $\gamma$ complex has been implicated in crossover-biased resolution ${ }^{7-12}$, the mechanisms that activate and direct strand-specific cleavage remain unknown. Here we show that the sliding clamp, PCNA, is important for crossover-biased resolution. In vitro assays with human enzymes show that hPCNA and its loader hRFC are sufficient to activate the hMutL $\gamma$ endonuclease under physiological conditions. In this context, the hMutL $\gamma$ endonuclease is further stimulated by a co-dependent activity of the pro-crossover factors hEXO1 and hMutS $\gamma$, the latter of which binds Holliday junctions ${ }^{13}$. hMutL $\gamma$ also specifically binds a variety of branched DNAs, including Holliday junctions, but canonical resolvase activity is not observed implying that the endonuclease incises adjacent to junction branch points to effect resolution. In vivo, we show that budding yeast RFC facilitates MutL $\gamma$ dependent crossing over. Furthermore, PCNA localizes to prospective crossover sites along synapsed chromosomes. These data highlight similarities between crossover-resolution and DNA mismatch repair ${ }^{14-16}$ and evoke a novel model for crossover-specific dHJ resolution during meiosis. 


\section{Main}

Meiotic recombination is initiated by programmed DNA double-strand breaks (DSBs) and proceeds via homologous pairing and DNA strand-exchange to form joint-molecule (JM) intermediates ${ }^{1}$. Regulatory processes designate a subset of events to become crossovers, and at these sites nascent JMs are matured into double-Holliday junctions (dHJs). Through poorly defined mechanisms, MutL $\gamma$ (comprising MLH1 and MLH3) accumulates at prospective crossover sites and biases $\mathrm{dHJ}$ resolution to specifically produce crossovers ${ }^{17,18}$. When MutL $\gamma$ is dysfunctional, dHJs are still resolved, but with a non-crossover outcome ${ }^{8}$. Consequently, chromosome segregation fails and fertility is diminished. MLH1 and MLH3 are conserved members of the MutL family of DNA mismatch-repair (MMR) factors that couple mismatchrecognition by a MutS complex to downstream excision and resynthesis of the nascent strand $^{14,16}$. MutL complexes from diverse species possess endonuclease activity that provides an initiation site for mismatch excision by a $5^{\prime}-3$ exonuclease such as EXO $1^{15}$. During DNA replication, MutL-catalyzed incision, and thus MMR, is specifically targeted to the nascent strand via an orientation-specific interaction with the replicative clamp, PCNA or the $\beta$-clamp in eukaryotes and prokaryotes, respectively ${ }^{19-22}$. Endonuclease activity has been demonstrated for budding yeast and human MutL $\gamma^{10-12,23,24}$ and the conserved metal-binding active site in MLH3 is required for crossing over in both yeast ${ }^{7,8}$ and mouse ${ }^{9}$. However, how the MutL $\gamma$ endonuclease is activated and directed to effect crossover-specific resolution of dHJs remains unknown.

\section{Human MutL $\gamma$ is an endonuclease}

Human MutL $\gamma$ (hMutL $\gamma$ ) was purified from insect cells (Fig.1a,b and Extended Data Fig. 1) and endonuclease activity monitored using a supercoiled-plasmid DNA nicking assay (Fig.1c). In isolation, hMutL $\gamma$ displayed a concentration-dependent nicking activity that plateaued at $\sim 40 \%$ of input DNA with $100 \mathrm{nM}$ MutL $\gamma$ (Fig.1d-f). Activity required $\mathrm{Mn}^{2+}$ and the metal-binding site of 
$\mathrm{hMLH} 3$, indicating that nuclease activity was specific to hMutL $\gamma$. Endonuclease activity of hMutLy was not seen in $\mathrm{Mg}^{2+}$, which is inferred to be the physiological metal cofactor ${ }^{15,19}$ (Extended Data Fig. 1). Although $\mathrm{Zn}^{2+}$ is present at MutL active sites ${ }^{15}$, nicking was also negligible with $\mathrm{Zn}^{2+}$, as well as $\mathrm{Ca}^{2+}, \mathrm{Ni}^{2+}, \mathrm{Co}^{2+}$ or $\mathrm{Cd}^{2+}$ (Extended Data Fig. 1). However, these metals were able to compete with $\mathrm{Mn}^{2+}$ to inhibit hMutL $\gamma$ endonuclease activity suggesting that $\mathrm{Mn}^{2+}$ is relatively weakly bound, and likely to be non-physiological ${ }^{15}$. The strict dependence on $\mathrm{Mn}^{2+}$ is anlogous to human and yeast MutLa complexes (MLH1-PMS2 and Mlh1-Pms1, respectively) when assayed in isolation ${ }^{19,25}$, but contrasts yeast MutLY, which was reported to show endonuclease activity with a range of metals including $\mathrm{Mn}^{2+}, \mathrm{Co}^{2+}, \mathrm{Ca}^{2+}$ and $\mathrm{Mg}^{2+11}$.

MutL proteins are ATPases; binding and hydrolysis of ATP is required for the mismatch correction and meiotic crossover functions of yeast MutLy in vivo ${ }^{26}$, and induces conformational changes in vitro ${ }^{23}$. Typically, ATP stimulates MutL endonuclease activity ${ }^{15}$, but surprisingly no stimulation was reported for budding yeast MutLy, raising the possibility that MutLy complexes are distinctly regulated ${ }^{10,11}$. On the contrary, we observed that the human MutL $\gamma$ endonuclease was stimulated 2-fold by ATP, when both $\mathrm{Mn}^{2+}$ and $\mathrm{Mg}^{2+}$ were present (Fig 1.g,h and Extended

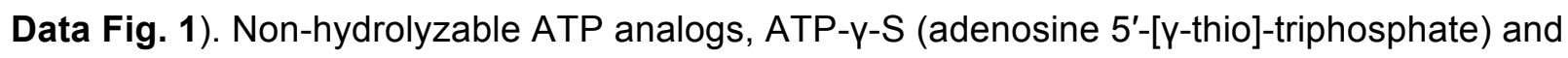
AMP-PNP (adenylyl-imidodiphosphate), did not stimulate the hMutLy endonuclease suggesting that ATP hydrolysis is required (Fig. $\mathbf{1 h}$ ).

\section{hMutSy stimulates hMutLY endonuclease activity}

The MutS $\gamma$ complex, MSH4-MSH5, specifically binds JM structures ${ }^{13,27}$ and plays an earlier and more general role than MutL $\gamma$ in meiotic recombination, localizing to a majority of recombination sites where it stabilizes nascent JMs to facilitate chromosome synapsis ${ }^{1,17,27,28}$. The MMR paradigm predicts that MutS $\gamma$ may also guide and trigger the MutL $\gamma$ endonuclease ${ }^{14,16}$. However, MutL $\gamma$ has its own JM binding activity ${ }^{10,23}$ (below), appears on synapsed chromosomes much 
later than MutS $\gamma$, and localizes only to crossover sites ${ }^{1,17,28}$, raising the possibility that MutL $\gamma$ acts autonomously during $\mathrm{dHJ}$ resolution. Moreover, previous analysis of the yeast enzymes did not detect any stimulation of the MutL $\gamma$ endonuclease by MutS $\gamma^{10}$.

By co-immunostaining mouse spermatocyte chromosome spreads for MLH1 and MSH4, we determined that MutL $\gamma$ closely colocalized with a subset of MutS $\gamma$ foci as it first emerges at prospective crossover sites in the mid-pachytene stage (Fig. 2a,b and Extended Data Fig. 2). Co-localization appears to be transient as MSH4 foci subsequently disappeared in late pachytene, while MutL $\gamma$ persisted. This observation suggests that mammalian MutS $\gamma$ and MutL $\gamma$ may transiently interact to modulate MutL $\gamma$ endonuclease activity. To test this possibility, human MutS $\gamma$ (hMutS $\gamma$ ) was purified and added to hMutL $\gamma$ nicking assays (Fig. 2c-e and Extended Data Fig. 3). In end-point analysis, we observed a modest stimulation ( 20\%) of MutL $\gamma$ endonuclease by MutS $\gamma$ that was ATP dependent (Fig. 2d). Time-course analysis confirmed this inference and revealed an accelerated rate of nicking when MutS $\gamma$ was present, with product reaching $50 \%$ of maximum by $16 \mathrm{~min}$, compared to $22 \mathrm{~min}$ for MutL $\gamma$ alone (Fig. 2e). Notably, MutS $\gamma$ provoked formation of a linearized plasmid product that arose with the same timing as nicked product implying localized concerted incision of both DNA strands by MutL $\gamma$.

A nuclease-independent activity of EXO1 facilitates crossing over along the same pathway as MutL $\gamma^{29,30}$. We also examined whether nuclease-dead hEXO1-D173A could enhance hMutL $\gamma$ endonuclease, with or without hMutS $\gamma$, but no additional stimulation was seen in the presence of $\mathrm{Mn}^{2+}, \mathrm{Mg}^{2+}$ and ATP (Fig. 2f-h, but see below and Fig. 3).

\section{RFC-PCNA activates the hMutL $\gamma$ endonuclease under physiological conditions}

Although $\mathrm{Mn}^{2+}$ activates MutL endonucleases, its physiological relevance is questionable ${ }^{15} . \ln$ reconstituted mismatch-repair reactions with $\mathrm{Mg}^{2+}$ as the sole metal cofactor, MutL complexes are latent endonucleases that are triggered only in the presence of heteroduplex DNA, a 
cognate MutS complex, and loaded replicative clamp ${ }^{15,19,21}$. When the human clamp, hPCNA, and its DNA loader, hRFC, were added to hMutL $\gamma$ endonuclease reactions with $\mathrm{Mn}^{2+}$ and ATP, nicking was enhanced more than two fold, but only for an ensemble including both hMutS $\gamma$ and hEXO1-D173A, implying concerted action of all five proteins (Fig. 3a-c). Strikingly, hRFChPCNA strongly activated the latent hMutL $\gamma$ endonuclease when $\mathrm{Mg}^{2+}$ was the sole metal cofactor (Fig. 3d). While hRFC-hPCNA alone could trigger the hMutL $\gamma$ endonuclease, nicking was further stimulated $\sim 1.5$-fold when both hMutS $\gamma$ and hEXO1-D173A were also present, i.e. under physiological conditions hMutS $\gamma$ and hEXO1-D173A appear to act as an interdependent stimulatory factor. Time-course analysis confirmed that MutS $\gamma$-EXO1-D173A increased product yield, but not the rate of formation (Fig. 3e,f; nicked product reached $50 \%$ of maximum by 9 and $10 \mathrm{~min}$, respectively with and without MutS $\gamma$-EXO1-D173A). In $\mathrm{Mg}^{2+}$-only reactions, activation was absolutely dependent on both hRFC (Fig. 3d, lane 9) and ATP (Fig. 3g), implying that hPCNA must be loaded onto DNA to activate hMutL $\gamma$. Moreover, hPCNA and hMutL $\gamma$ interacted in solution, suggesting that activation occurs through direct physical interaction between the two proteins (Extended Data Fig. 4). Importantly, in these ensemble reactions, all nuclease activity required the metal-binding site of $\mathrm{hMLH} 3$, ruling out any contribution from contaminating nucleases (Fig. 3h).

\section{Holliday junctions are specifically bound by hMutL $\gamma$ and enhance endonuclease activity}

Both budding yeast and human MutL $\gamma$ preferentially bind branched DNA structures, including Holliday junctions $(\mathrm{HJs})^{10,23}$, although Ranjha et al. reported that binding was very sensitive to salt and $\mathrm{Mg}^{2+10}$. In our hands, hMutL $\gamma$ selectively bound a broad variety of branched DNA substrates, in the presence of physiological concentrations of salt and $\mathrm{Mg}^{2+}$, and excess competitor DNA (poly(dl-dC)) (Fig. 4a,b). Four-armed structures bound by hMutL $\gamma$ included the pro-HJ (pHJ) containing one single-stranded (ss) arm, which approximates an initial D-loop 
strand-invasion intermediate ${ }^{13}$; a HJ with a 20 nt single-stranded gap in one arm $(\mathrm{gHJ})$, a $\mathrm{HJ}$ with a nick at the junction point $(\mathrm{nHJ})$; and a standard $\mathrm{HJ}(\mathrm{HJ}$; Fig. 4a). HJs and $\mathrm{nHJ}$ sere bound with very similar affinities (apparent $K_{d} \sim 38$ and $\sim 39 \mathrm{nM}$, respectively; Fig. $4 \mathbf{b}$ ) indicating that additional flexibility around the junction point does not influence hMutL $\gamma$ binding (unlike, for example, the structure-selective endonuclease Mus81-Mms4 $\left.{ }^{\mathrm{EME} 1},{ }^{31}\right)$. hMutL $\gamma$ had significantly higher affinities for the $\mathrm{pHJ}$ and $\mathrm{gHJ}$ substrates (apparent $K_{d} \sim 14$ and $16 \mathrm{nM}$, respectively) suggesting that ssDNA enhances binding (Fig. 4b). Indeed, analogous to the budding yeast enzyme ${ }^{23}$, hMutL $\gamma$ was able to interact with ssDNA, as shown by its specific binding to a $40 \mathrm{nt}$ poly-dT ssDNA substrate (Extended Data Fig. 5). To define the minimal internal ssDNA region that can be efficiently bound by hMutL $\gamma, 80 \mathrm{nt}$ linear DNAs containing single-strand gaps of varying lengths were tested (Fig. 4c). Significant binding was not detected for gaps of 5 and 10 nt, but 20 and 40 nt gaps were bound efficiently (Fig. 4d). Notably, this minimal binding site is similar to that bound by the canonical ssDNA binding protein RPA ${ }^{32}$. However, RPA binds ssDNA with sub-nanomolar affinity and is therefore predicted to block binding by hMutL $\gamma$. Consistently, RPA blocked hMutL $\gamma$ from binding to a 40 nt gap substrate (Fig. 4e). To test whether the branched and ssDNA binding activities are autonomous, $\mathrm{gHJ}$ and $\mathrm{pHJ}$ substrates were pre-incubated with RPA and then used as binding substrates for hMutL $\gamma$ (Fig. 4g). RPAgHJ and RPA-pHJ complexes were still readily bound by hMutL $\gamma$, but affinities decreased to below that of a HJ (Fig. 1h). Thus, as shown by Claeys Bouuaert et al. for yeast MutL $\gamma^{23}$, the junction and ssDNA binding activities of hMutL $\gamma$ appear to be largely independent.

Despite the intrinsic JM binding ability of $\mathrm{hMutL} \gamma$, resolution or even nicking of model HJcontaining substrates was not detected (Extended Data Fig. 6) implying that hMutL $\gamma$ cannot catalyze symmetric incisions across the junction, i.e. is not a classical $\mathrm{HJ}$ resolving enzyme ${ }^{33}$. However, the presence of a $\mathrm{HJ}$ did influence the binding and incision of a plasmid substrate 
(Fig. 4i-k and Extended Data Fig. 7). pUC(AT) contains an (AT) $)_{20}$ inverted repeat that extrudes into a four-way hairpin junction upon supercoiling, but is otherwise identical to pUC19 $19^{34}$. By agarose-gel electrophoresis, a heterogeneous smear of hMutL $\gamma-p U C 19$ complexes was observed suggesting unstable binding (Fig. 4i). By contrast, hMutL $\gamma-p U C(A T)$ complexes migrated as relatively discrete species and overall efficiency of stable complex formation was much higher (Fig. 4j). Moreover, the decreasing mobility of hMutL $\gamma-p U C(A T)$ complexes observed with increasing hMutL $\gamma$ concentration points to formation of higher-order complexes analogous to the cooperative, multimeric oligomers described for yeast MutL $\gamma^{12,23}$.

In ensemble plasmid-nicking reactions with $\mathrm{Mg}^{2+}$ and ATP, pUC(AT) was incised up to 23\% more efficiently than pUC19 (Fig. 4k, lanes 5 and 11; and Extended Data Fig. 7). Analogous to pUC19, pUC(AT) cleavage was most efficient when hMutL $\gamma$, hMutS $\gamma$, hEXO1-D173A and hRFChPCNA were present, with hMutS $\gamma$ and EXO1-D173A appearing to function interdependently. Distinct from pUC19, however, pUC(AT) incision was not absolutely dependent on hRFChPCNA, with $\sim 15 \%$ nicked product being formed in reactions containing hMutL $\gamma$, hMutS $\gamma$ and hEXO1-D173A (Fig. 4k, lanes 4, 9 and 10). Thus, the HJ in pUC(AT) modulates both the binding and incision of DNA by hMutL $\gamma$.

\section{RFC-PCNA facilitates MutL $\gamma$-dependent crossing over}

A role for RFC-PCNA in MutL $\gamma$-dependent crossing over was demonstrated in vivo in budding yeast (Fig. 5). An auxin-inducible degron (AID) allele of Rfc1 was employed to inactivate RFC, and thereby prevent PCNA loading, precisely at the time of $\mathrm{dHJ}$ resolution (Fig. 5a; note that AID alleles of PCNA were not functional). An inducible allele of the NDT80 gene allowed reversible arrest of cells at the pachytene stage of meiosis, in which chromosomes are fullysynapsed and $\mathrm{dHJ}$ are poised for resolution ${ }^{35,36}$. Following release from arrest and addition of 
auxin, Rfc1-AID was rapidly degraded (Fig. 5b,c) and crossing over at a recombination hotspot, monitored by Southern analysis, was reduced from $17.5 \%( \pm 2.2 \%$ SEM $)$ to $10.4 \%( \pm 1.8 \%$ SEM) (Fig. 5d,e). Similar analysis of RFC1-AID mlh3 $\Delta$ cells indicated that RFC promotes primarily MutL $\gamma$-dependent crossovers. However, approximately one-third of $M L H 3$-independent crossovers also appeared to be RFC dependent, which may be explained by the ability of RFCPCNA to also stimulate the structure-selective endonuclease, Mus81-Mms4 ${ }^{\text {EME1 } 37}$, which defines a second crossover pathway in budding yeast ${ }^{8}$. Rfc1-AID degradation did not alter the timing or efficiency of $\mathrm{dHJ}$ resolution indicating that the crossover outcome, but not resolution per se, is facilitated by RFC-PCNA (Fig. 5f, and Extended Data Fig. 8). Under these conditions, $m / h 3 \Delta$ mutation did delay dHJ turnover, but resolution was ultimately efficient and Rfc1-AID degradation did not further alter the timing or efficiency of resolution.

Consistent with a role for RFC-PCNA in crossing over, PCNA localized to a subset of prospective crossover sites marked by the Zip3 protein (Fig. $\mathbf{5 g})^{38}$. In chromosome spreads from cells arrested in pachytene, PCNA and Zip3 immunostaining foci averaged $15.4( \pm 1.1$ SEM) and 47.2 ( \pm 1.3 SEM), respectively ( $n=25$ nuclei); and $85.1 \%( \pm 1.9 \%$ SD) of PCNA foci colocalized with Zip3.

\section{Discussion}

Asymmetric incision is required for the crossover-biased resolution of dHJs during meiosis, but how asymmetry is imposed has remained unclear. The requirements for MutS $\gamma$, MutL $\gamma$ and EXO1 in meiotic crossing over evoked a MMR-like mechanism, involving MutL $\gamma$-catalyzed nicking of $\mathrm{dHJs}^{1,17,18}$. Our discoveries implicating RFC-PCNA in MutL $\gamma$-dependent crossing over strongly suggest that $\mathrm{dHJ}$ resolution is indeed fundamentally analogous to canonical MMR. We propose a specific model for crossover-specific $\mathrm{dHJ}$ resolution in which orientation-specific 
loading of PCNA, during the DNA synthesis associated with $\mathrm{dHJ}$ formation, directs MutL $\gamma$ to incise specific DNA strands on both sides of the junction points (Fig. 5h). In reconstituted MMR reactions, PCNA, loaded at a nick, signals over hundreds of base pairs to direct incision of the same non-continuous strand by MutL $\alpha^{14-16}$. While incisions are biased upstream of the mismatch, in order to initiate excision by the 5'-3' exonuclease EXO1, nicking also occurs at downstream locations. By analogy, we propose that the PCNA molecules involved in recombination-associated DNA synthesis direct strand-specific nicking by MutL $\gamma$ on both sides of the two HJs (Fig. 5h). Resolution occurs only when the HJs adopt one of the two co-axially stacked-X conformers, which could be favored by the binding of MutS $\gamma^{27}$ or other pro-crossover factors, and always specifies a crossover outcome. We suggest that the near continuous duplexes formed by the stacked $\mathrm{HJ}$ arms enable the strand-specificity of PCNA-directed MutL $\gamma$ catalyzed incision to be maintained across the junction point, even though the targeted strands are not contiguous. Given that nicking occurs some distance from the exchange points, our model predicts that junction migration via a helicase will be required for crossover-specific $\mathrm{dHJ}$ resolution, consistent with the known role of the RecQ-family helicase Sgs $1 / B_{L} M^{8,39}$. Our model provides a solution to the critical question of how a crossover outcome is enforced at designated sites to help ensure accurate chromosome segregation during meiosis.

1 Hunter, N. Meiotic Recombination: The Essence of Heredity. Cold Spring Harbor perspectives in biology 7, doi:10.1101/cshperspect.a016618 (2015).

2 Wang, S., Zickler, D., Kleckner, N. \& Zhang, L. Meiotic crossover patterns: obligatory crossover, interference and homeostasis in a single process. Cell cycle 14, 305-314, doi:10.4161/15384101.2014.991185 (2015).

3 Schwacha, A. \& Kleckner, N. Identification of double Holliday junctions as intermediates in meiotic recombination. Cell 83, 783-791 (1995). 
4 Allers, T. \& Lichten, M. Differential timing and control of noncrossover and crossover recombination during meiosis. Cell 106, 47-57 (2001).

5 Marsolier-Kergoat, M. C., Khan, M. M., Schott, J., Zhu, X. \& Llorente, B. Mechanistic view and genetic control of DNA recombination during meiosis. Molecular cell 70, 9-20 e26, doi:10.1016/j.molcel.2018.02.032 (2018).

6 Szostak, J. W., Orr-Weaver, T. L., Rothstein, R. J. \& Stahl, F. W. The double-strandbreak repair model for recombination. Cell 33, 25-35 (1983).

7 Nishant, K. T., Plys, A. J. \& Alani, E. A mutation in the putative MLH3 endonuclease domain confers a defect in both mismatch repair and meiosis in Saccharomyces cerevisiae. Genetics 179, 747-755, doi:10.1534/genetics.108.086645 (2008).

8 Zakharyevich, K., Tang, S., Ma, Y. \& Hunter, N. Delineation of joint molecule resolution pathways in meiosis identifies a crossover-specific resolvase. Cell 149, 334-347, doi:10.1016/j.cell.2012.03.023 (2012).

9 Toledo, M. et al. A mutation in the endonuclease domain of mouse MLH3 reveals novel roles for MutLgamma during crossover formation in meiotic prophase I. PLoS genetics 15, e1008177, doi:10.1371/journal.pgen.1008177 (2019).

10 Ranjha, L., Anand, R. \& Cejka, P. The Saccharomyces cerevisiae Mlh1-Mlh3 heterodimer is an endonuclease that preferentially binds to Holliday junctions. The Journal of biological chemistry 289, 5674-5686, doi:10.1074/jbc.M113.533810 (2014).

11 Rogacheva, M. V. et al. Mlh1-Mlh3, a meiotic crossover and DNA mismatch repair factor, is a Msh2-Msh3-stimulated endonuclease. The Journal of biological chemistry 289, 5664-5673, doi:10.1074/jbc.M113.534644 (2014).

12 Manhart, C. M. et al. The mismatch repair and meiotic recombination endonuclease Mlh1-Mlh3 is activated by polymer formation and can cleave DNA substrates in trans. PLoS biology 15, e2001164, doi:10.1371/journal.pbio.2001164 (2017). 
13 Snowden, T., Acharya, S., Butz, C., Berardini, M. \& Fishel, R. hMSH4-hMSH5 recognizes Holliday Junctions and forms a meiosis-specific sliding clamp that embraces homologous chromosomes. Molecular cell 15, 437-451 (2004).

14 Iyer, R. R., Pluciennik, A., Burdett, V. \& Modrich, P. L. DNA mismatch repair: functions and mechanisms. Chem Rev 106, 302-323, doi:10.1021/cr0404794 (2006).

15 Kadyrova, L. Y. \& Kadyrov, F. A. Endonuclease activities of MutLalpha and its homologs in DNA mismatch repair. DNA repair 38, 42-49, doi:10.1016/j.dnarep.2015.11.023 (2016).

16 Kolodner, R. D. A personal historical view of DNA mismatch repair with an emphasis on eukaryotic DNA mismatch repair. DNA repair $38,3-13$, doi:10.1016/j.dnarep.2015.11.009 (2016).

17 Manhart, C. M. \& Alani, E. Roles for mismatch repair family proteins in promoting meiotic crossing over. DNA repair 38, 84-93, doi:10.1016/j.dnarep.2015.11.024 (2016).

18 Gray, S. \& Cohen, P. E. Control of Meiotic Crossovers: From Double-Strand Break Formation to Designation. Annual review of genetics 50, 175-210, doi:10.1146/annurevgenet-120215-035111 (2016).

19 Kadyrov, F. A., Dzantiev, L., Constantin, N. \& Modrich, P. Endonucleolytic function of MutLalpha in human mismatch repair. Cell 126, 297-308 (2006).

20 Pluciennik, A. et al. PCNA function in the activation and strand direction of MutLalpha endonuclease in mismatch repair. Proceedings of the National Academy of Sciences of the United States of America 107, 16066-16071, doi:10.1073/pnas.1010662107 (2010).

21 Pillon, M. C. et al. Structure of the endonuclease domain of MutL: unlicensed to cut. Molecular cell 39, 145-151, doi:10.1016/j.molcel.2010.06.027 (2010).

22 Pillon, M. C. et al. The sliding clamp tethers the endonuclease domain of MutL to DNA. Nucleic acids research 43, 10746-10759, doi:10.1093/nar/gkv918 (2015). 
23 Claeys Bouuaert, C. \& Keeney, S. Distinct DNA-binding surfaces in the ATPase and linker domains of MutLgamma determine its substrate specificities and exert separable functions in meiotic recombination and mismatch repair. PLoS genetics 13, e1006722, doi:10.1371/journal.pgen.1006722 (2017).

24 Kadyrova, L. Y., Gujar, V., Burdett, V., Modrich, P. L. \& Kadyrov, F. A. Human MutLgamma, the MLH1-MLH3 heterodimer, is an endonuclease that promotes DNA expansion. Proceedings of the National Academy of Sciences of the United States of America, doi:10.1073/pnas.1914718117 (2020).

25 Kadyrov, F. A. et al. Saccharomyces cerevisiae MutLalpha is a mismatch repair endonuclease. The Journal of biological chemistry 282, 37181-37190, doi: 10.1074/jbc.M707617200 (2007).

26 Sonntag Brown, M., Lim, E., Chen, C., Nishant, K. T. \& Alani, E. Genetic analysis of mlh3 mutations reveals interactions between crossover promoting factors during meiosis in baker's yeast. G3 3, 9-22, doi:10.1534/g3.112.004622 (2013).

27 Lahiri, S., Li, Y., Hingorani, M. M. \& Mukerji, I. MutSgamma-Induced DNA Conformational Changes Provide Insights into Its Role in Meiotic Recombination. Biophys J 115, 2087-2101, doi:10.1016/j.bpj.2018.10.029 (2018).

28 Svetlanov, A. \& Cohen, P. E. Mismatch repair proteins, meiosis, and mice: understanding the complexities of mammalian meiosis. Experimental cell research 296, 71-79, doi:10.1016/j.yexcr.2004.03.020 (2004).

29 Zakharyevich, K. et al. Temporally and biochemically distinct activities of Exo1 during meiosis: double-strand break resection and resolution of double Holliday junctions. Molecular cell 40, 1001-1015, doi:10.1016/j.molcel.2010.11.032 (2010).

30 Schaetzlein, S. et al. Mammalian Exo1 encodes both structural and catalytic functions that play distinct roles in essential biological processes. Proceedings of the National 
Academy of Sciences of the United States of America 110, E2470-2479, doi:10.1073/pnas.1308512110 (2013).

31 Mukherjee, S., Wright, W. D., Ehmsen, K. T. \& Heyer, W. D. The Mus81-Mms4 structure-selective endonuclease requires nicked DNA junctions to undergo conformational changes and bend its DNA substrates for cleavage. Nucleic acids research 42, 6511-6522, doi:10.1093/nar/gku265 (2014).

32 Kumaran, S., Kozlov, A. G. \& Lohman, T. M. Saccharomyces cerevisiae replication protein A binds to single-stranded DNA in multiple salt-dependent modes. Biochemistry 45, 11958-11973, doi:10.1021/bi060994r (2006).

33 Wyatt, H. D. \& West, S. C. Holliday junction resolvases. Cold Spring Harbor perspectives in biology 6, a023192, doi:10.1101/cshperspect.a023192 (2014).

34 Eichman, B. F., Vargason, J. M., Mooers, B. H. \& Ho, P. S. The Holliday junction in an inverted repeat DNA sequence: sequence effects on the structure of four-way junctions. Proceedings of the National Academy of Sciences of the United States of America 97, 3971-3976, doi:10.1073/pnas.97.8.3971 (2000).

35 Carlile, T. M. \& Amon, A. Meiosis I is established through division-specific translational control of a cyclin. Cell 133, 280-291, doi:10.1016/j.cell.2008.02.032 (2008).

36 Tang, S., Wu, M. K. Y., Zhang, R. \& Hunter, N. Pervasive and essential roles of the Top3-Rmi1 decatenase orchestrate recombination and facilitate chromosome segregation in meiosis. Molecular cell 57, 607-621, doi:10.1016/j.molcel.2015.01.021 (2015).

37 Sisakova, A., Altmannova, V., Sebesta, M. \& Krejci, L. Role of PCNA and RFC in promoting Mus81-complex activity. BMC Biol 15, 90, doi:10.1186/s12915-017-0429-8 (2017).

38 Zhang, L. et al. Topoisomerase II mediates meiotic crossover interference. Nature 511, 551-556, doi:10.1038/nature13442 (2014). 
bioRxiv preprint doi: https://doi.org/10.1101/2020.02.12946020; this version posted February 13,2020 . The copyright holder for this preprint

(which was not certified by peer review) is the author/funder, who has granted bioRxiv a license to display the preprint in perpetuity. It is made available under aCC-BY-NC-ND 4.0 International license.

39 Hatkevich, T. \& Sekelsky, J. Bloom syndrome helicase in meiosis: Pro-crossover functions of an anti-crossover protein. BioEssays : news and reviews in molecular, cellular and developmental biology 39, doi:10.1002/bies.201700073 (2017). 


\section{a}

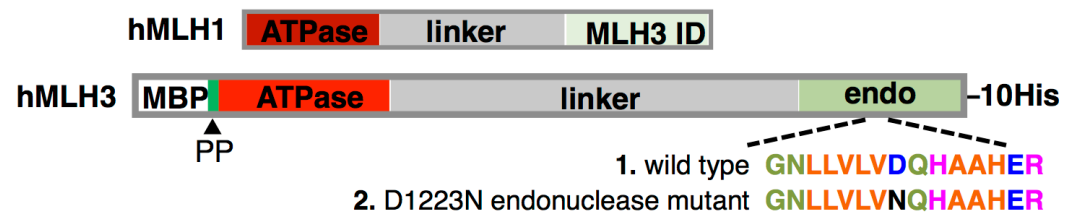

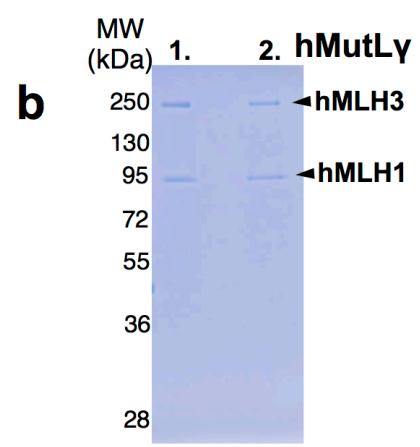

C

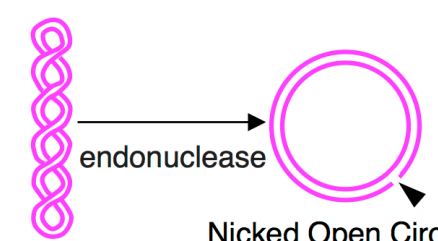

d

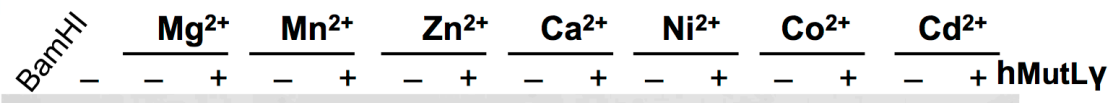

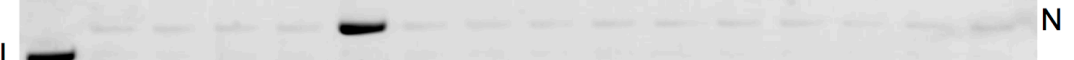

Supercoiled

(S)

(N)
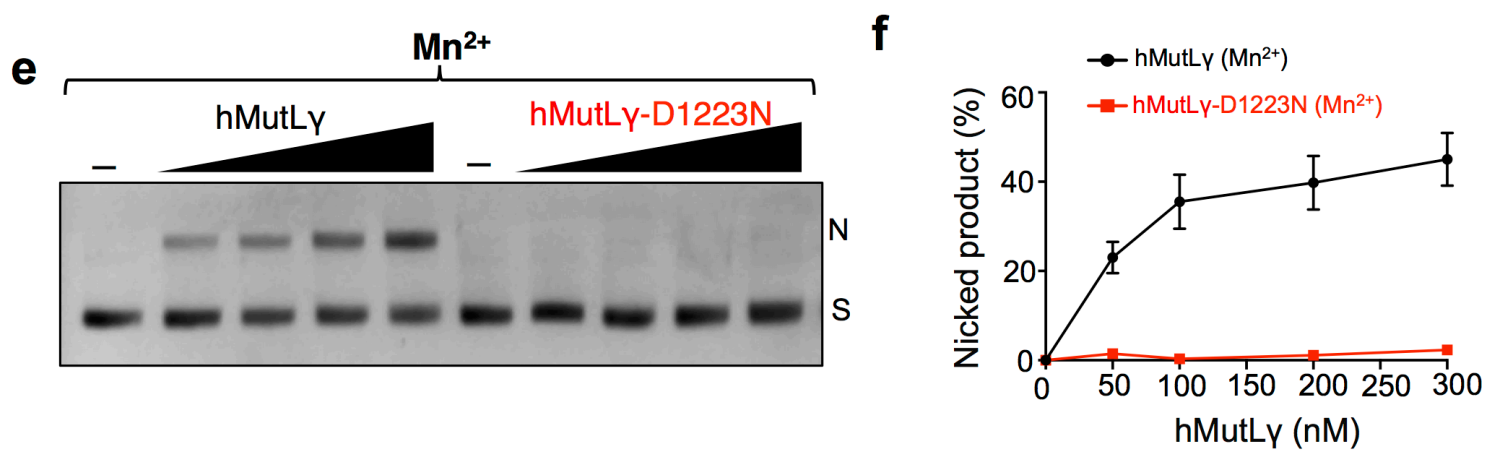

g

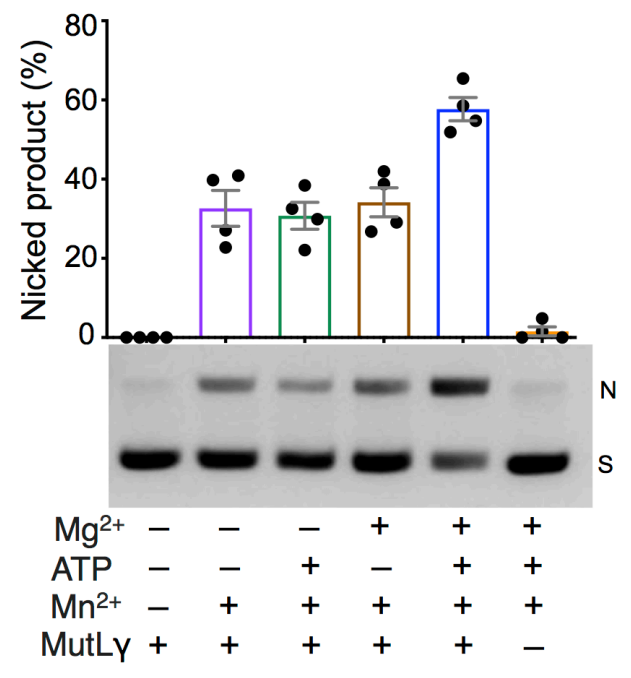

h

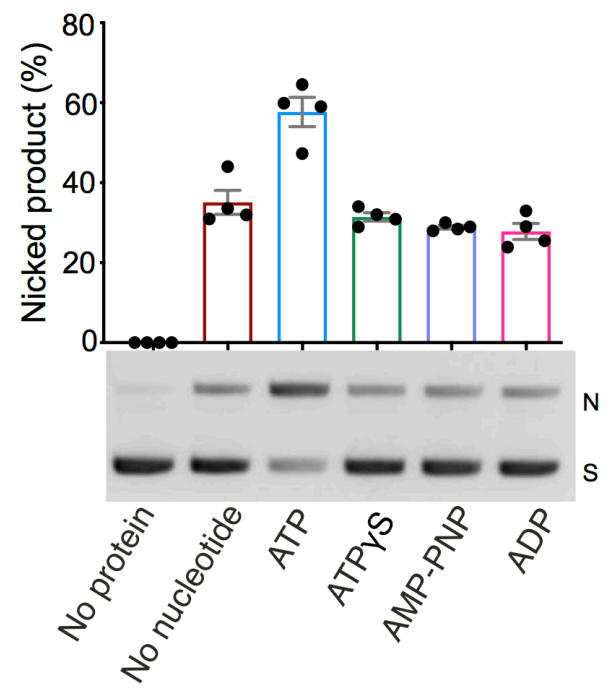


Figure 1. Endonuclease activity of human MutL $\gamma$. a, Illustration of hMLH1 and hMLH3 expression constructs highlighting domain structure and affinity-purification tags: MLH3 ID, hMLH3 interaction domain; endo, endonuclease domain; MBP, maltose binding protein; PP, PreScission protease cleavage site; $10 \mathrm{His}$, deca-histidine tag. Sequences of the conserved metal binding site for (1) wild-type and (2) the nuclease-dead D1223N mutant of MLH3 are also shown. b, SDS-PAGE analysis of purified hMutL $\gamma$ containing (1) wild-type hMLH3 and (2) mutant hMLH3-D1223N mutant (10\% gel stained with Coomassie; also see Extended Data Fig 1a). c, Supercoiled plasmid nicking assay used to study hMutL $\gamma$ endonuclease activity. d, Representative gel image showing hMutL $\gamma$ endonuclease assays with various metal ions (100 $\mathrm{nM} \mathrm{hMutL} \gamma$ and $5 \mathrm{mM}$ indicated divalent metal ions, incubated at $37^{\circ} \mathrm{C}$ for $\left.90 \mathrm{~min}\right)$. Migration positions of supercoiled $(\mathrm{S})$ plasmid and nicked $(\mathrm{N})$ product are shown. For reference, plasmid linearized $(\mathrm{L})$ with BamHI is also shown. \% N, percent nicked product. Means \pm SEM are shown for three experiments after subtracting background nicked product from no-protein controls. e, Endonuclease assays for varying concentrations of hMutL $\gamma$ and hMutL $\gamma-D 1223 \mathrm{~N}$ (0-300 nM protein and $5 \mathrm{mM} \mathrm{Mn}^{2+}$ incubated at $37^{\circ} \mathrm{C}$ for $60 \mathrm{~min} . \mathbf{f}$, Quantitation of experiments represented in panel e. Means \pm SEM are shown for three experiments. g, Representative gel image and quantification of hMutL $\gamma$ endonuclease activity with and without ATP and metal cofactors (100 nM hMutL $\gamma, 0.5 \mathrm{mM} \mathrm{ATP}$ and $5 \mathrm{mM} \mathrm{Mn}^{2+}$ and/or $\mathrm{Mg}^{2+}$ incubated at $37^{\circ} \mathrm{C}$ for $60 \mathrm{~min}$ ). Means \pm SEM are shown for four experiments. $\mathbf{h}$, Representative gel image and quantification of hMutL $\gamma$ endonuclease activity with indicated nucleotides and nucleotide analogs (100 nM hMutL $\gamma, 0.5$ $\mathrm{mM}$ nucleotide/analog, $5 \mathrm{mM} \mathrm{Mn}^{2+}$ and $5 \mathrm{mM} \mathrm{Mg}^{2+}$ incubated at $37^{\circ} \mathrm{C}$ for $60 \mathrm{~min}$ ). Means $\pm \mathrm{SEM}$ are shown for four experiments. 

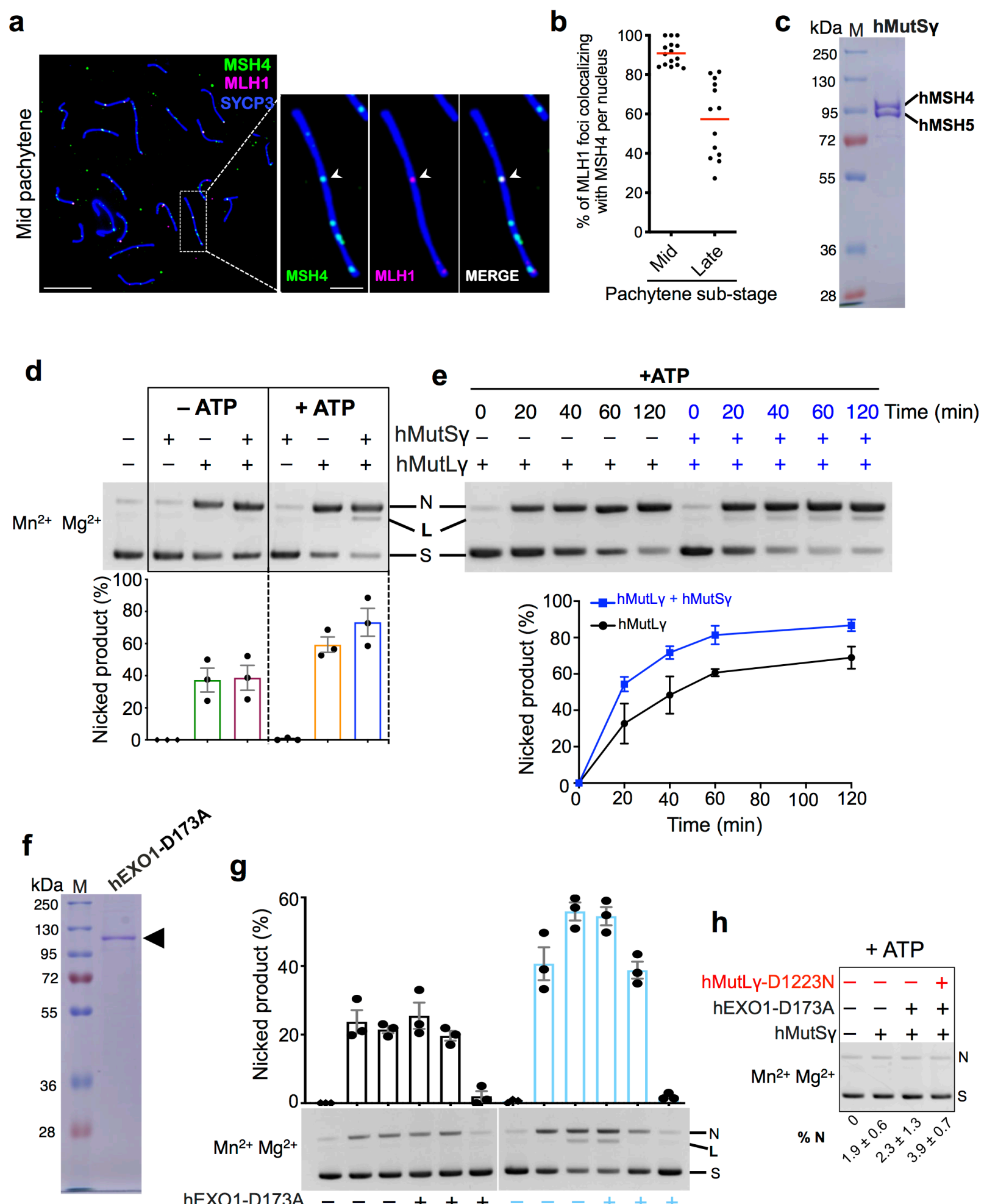

9
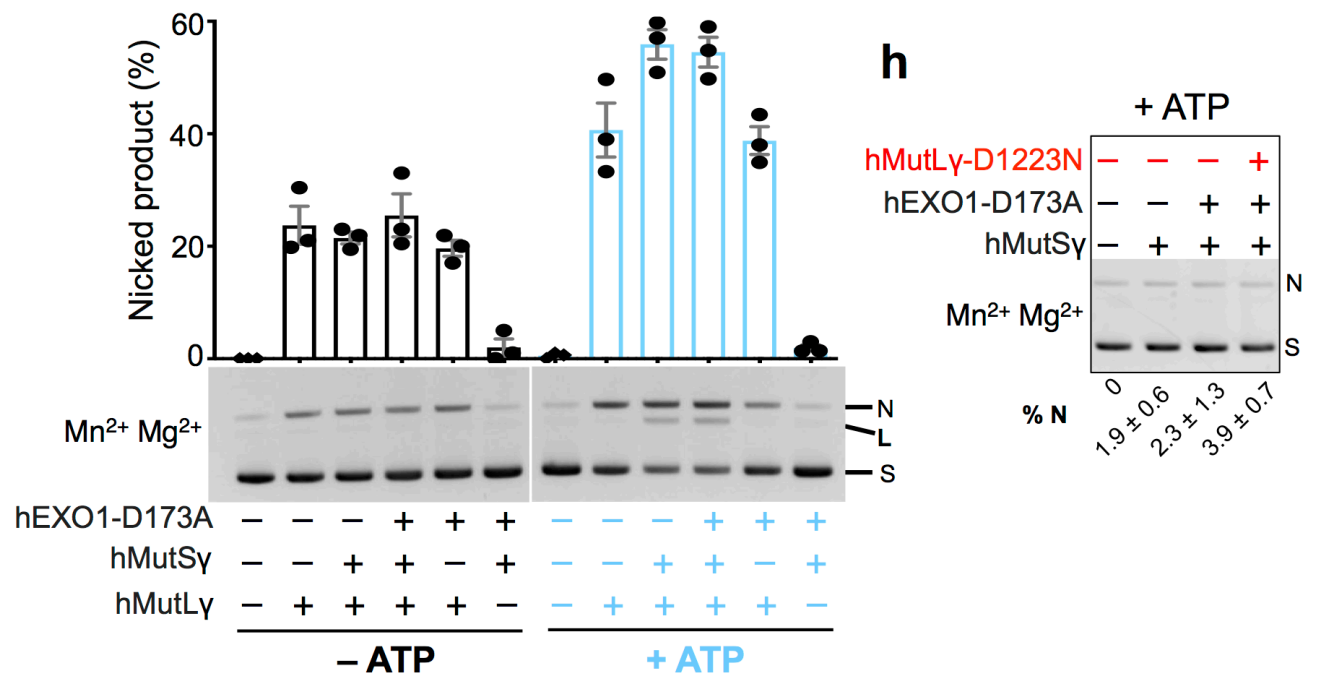
Figure 2. hMutS $\gamma$ stimulates hMutL $\gamma$ endonuclease activity. a, Representative image of surface-spread chromosomes from a mid-pachytene stage mouse spermatocyte, immunostained for MSH4 (green), MLH1 (magenta) and the chromosome axis marker SYCP3 (blue). Magnified panels show an individual pair of synapsed chromosomes in which a single crossover-specific MLH1 focus is colocalized with a MSH4 focus. b, Quantification of MLH1MSH4 colocalization in mid- and late-pachytene stages. c, SDS-PAGE analysis of purified hMutS $\gamma(10 \%$ gel stained with Coomassie; also see Extended Data Fig. 3a). d, Representative gel image and quantification of hMutL $\gamma$ endonuclease activity with and without hMutS $\gamma$ and ATP (100 nM hMutL $\gamma$ and hMutS $\gamma, 0.5 \mathrm{mM} \mathrm{ATP,} 5 \mathrm{mM} \mathrm{Mn}^{2+}$ and $\mathrm{Mg}^{2+}$, incubated at $37^{\circ} \mathrm{C}$ for $60 \mathrm{~min}$ ). Means \pm SEM are shown for three experiments. e, Time course analysis of hMutL $\gamma$ endonuclease activity with and without hMutS $\gamma$. A representative gel image and quantification of three independent experiments (means \pm SEM) are shown. Reaction conditions as described in panel d. f, SDS-PAGE analysis of purified nuclease-dead hEXO1-D173A (10\% gel stained with Coomassie). g, Endonuclease assays with varying mixtures of hMutL $\gamma$, hMutS $\gamma$ and hEXO1D173A, with and without ATP (50 nM each protein, $0.5 \mathrm{mM} \mathrm{ATP}, 5 \mathrm{mM} \mathrm{Mn}^{2+}$ and $\mathrm{Mg}^{2+}$ incubated at $37^{\circ} \mathrm{C}$ for $\left.60 \mathrm{~min}\right)$. Means $\pm \mathrm{SEM}$ are shown for three experiments. $\mathbf{h}$, Negative control endonuclease assays with nuclease-dead hMutL $\gamma$-D1223N, hMutS $\gamma$ and hEXO1-D173A Average percent nicking $(\% \mathrm{~N}) \pm \mathrm{SEM}$ are shown for three experiments. 


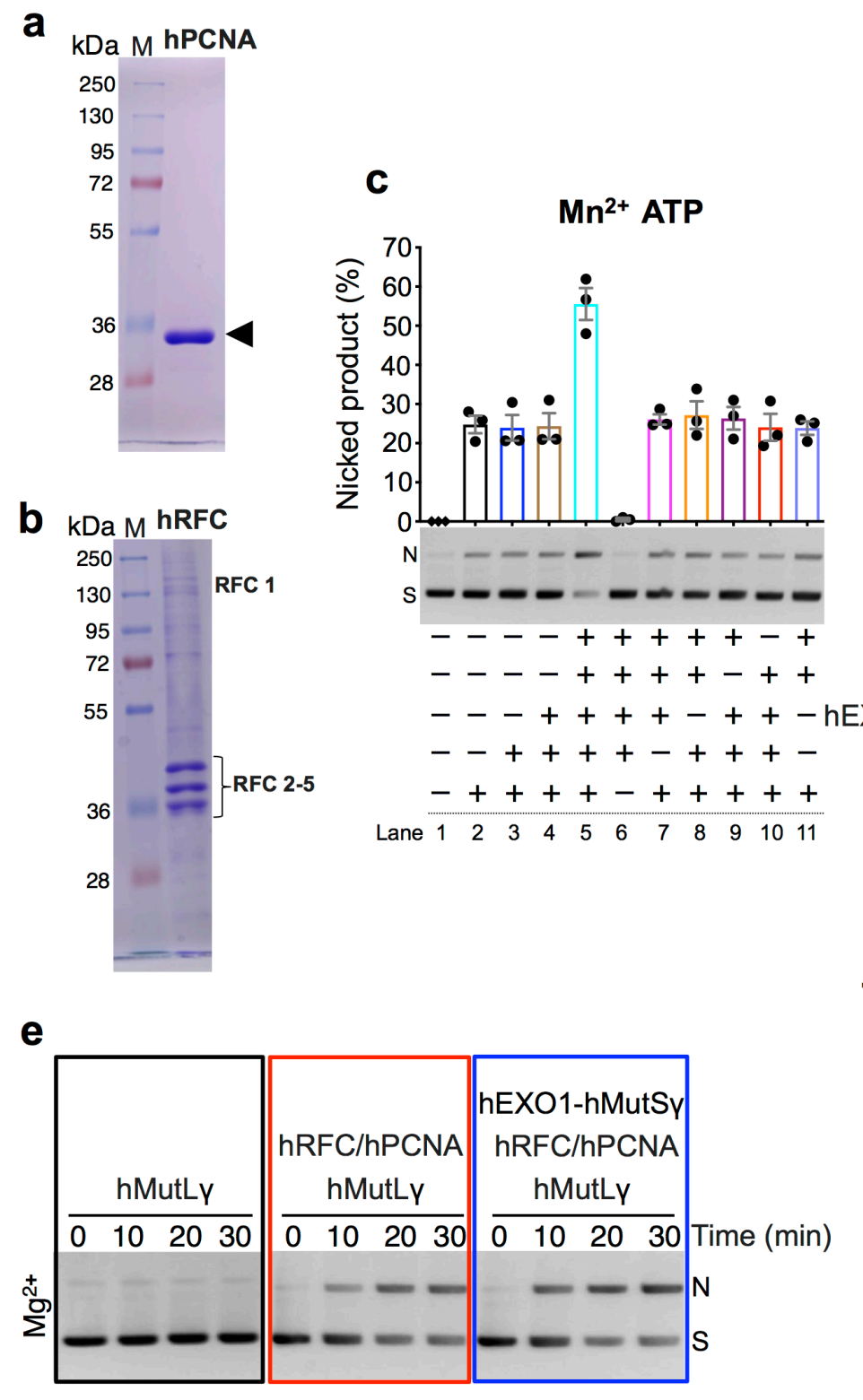

d

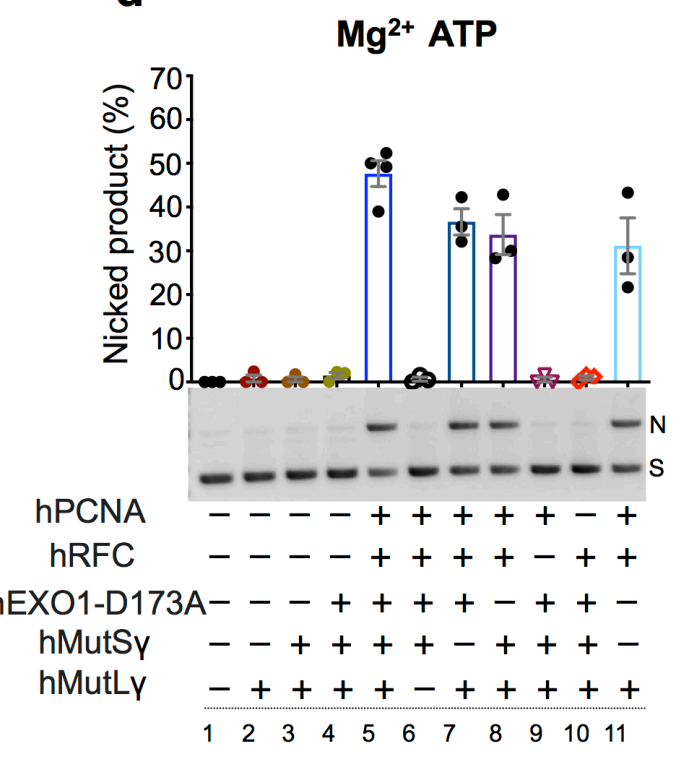

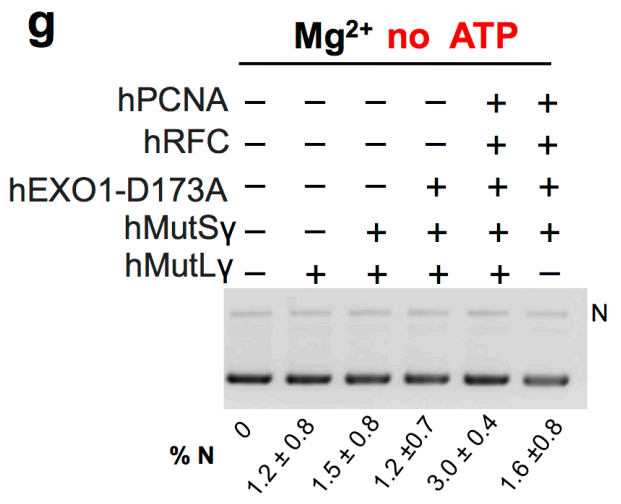

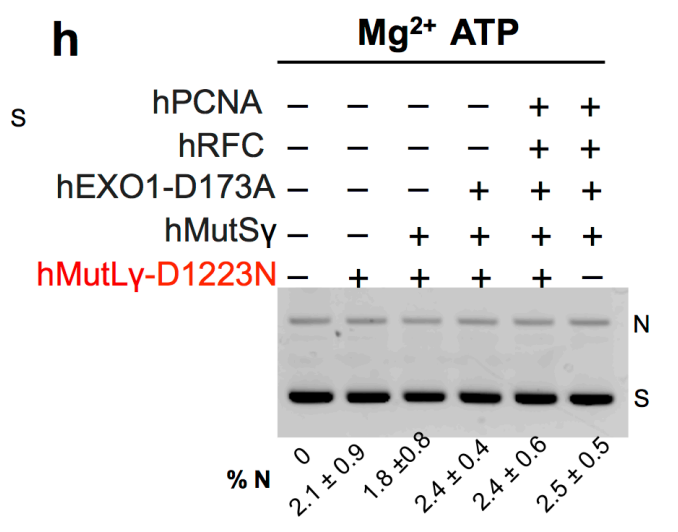


Figure 3. hRFC and hPCNA activate latent hMutLy endonuclease activity under

physiological conditions. a,b, SDS-PAGE analysis of purified hPCNA and hRFC (10\% gels

stained with Coomassie). c, Representative gel image and quantification of ensemble endonuclease reactions with $\mathrm{Mn}^{2+}$ as the sole metal cofactor. Reactions contained $25 \mathrm{nM}$ indicated proteins, $0.5 \mathrm{mM}$ ATP and $5 \mathrm{mM} \mathrm{Mn}^{2+}$ and were incubated at $37^{\circ} \mathrm{C}$ for $30 \mathrm{~min}$. Means \pm SEM are shown for three experiments. $\mathbf{d}$, Representative gel image and quantification of ensemble endonuclease reactions with $\mathrm{Mg}^{2+}$ as the sole metal cofactor. Reaction conditions were as described in panel $\mathbf{c}$, but with $5 \mathrm{mM} \mathrm{Mg}^{2+}$ instead of $\mathrm{Mn}^{2+}$. e,f, Time course analysis of hMutL $\gamma$ endonuclease activity in $\mathrm{Mg}^{2+}$, with and without hRFC/PCNA and hMutS $\gamma$-EXO1-D173A. A representative gel image (e) and quantification of three independent experiments (f, means \pm SEM) are shown. Reactions contained $25 \mathrm{nM}$ indicated proteins, $0.5 \mathrm{mM} \mathrm{ATP}$ and $5 \mathrm{mM} \mathrm{Mg}^{2+}$ and were incubated at $37^{\circ} \mathrm{C}$ for the indicated times. g, No ATP controls for ensemble reactions showing a representative gel image and quantification (means \pm SEM). Reaction conditions were as described in panel $\mathbf{d}$, but without ATP. $\mathbf{g}, \mathbf{h}$, Negative control for ensemble endonuclease assays with nuclease-dead hMutL $\gamma$-D1223N showing a representative gel image and quantification (means \pm SEM). $\% \mathrm{~N}$, percent nicking. 
a
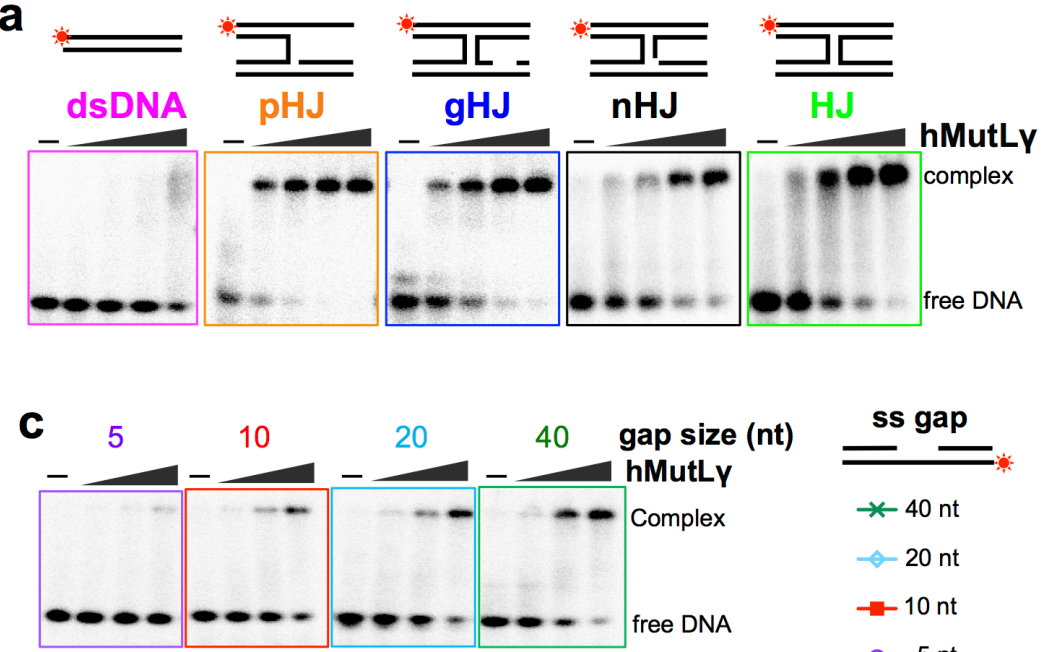

e

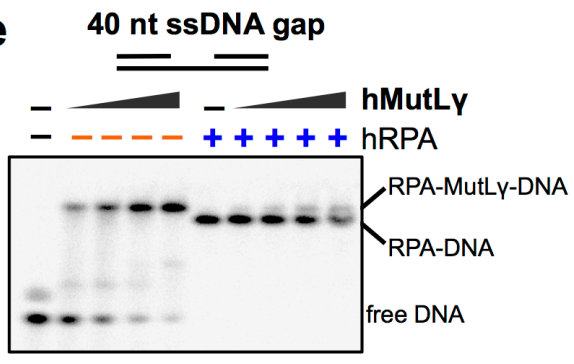

f
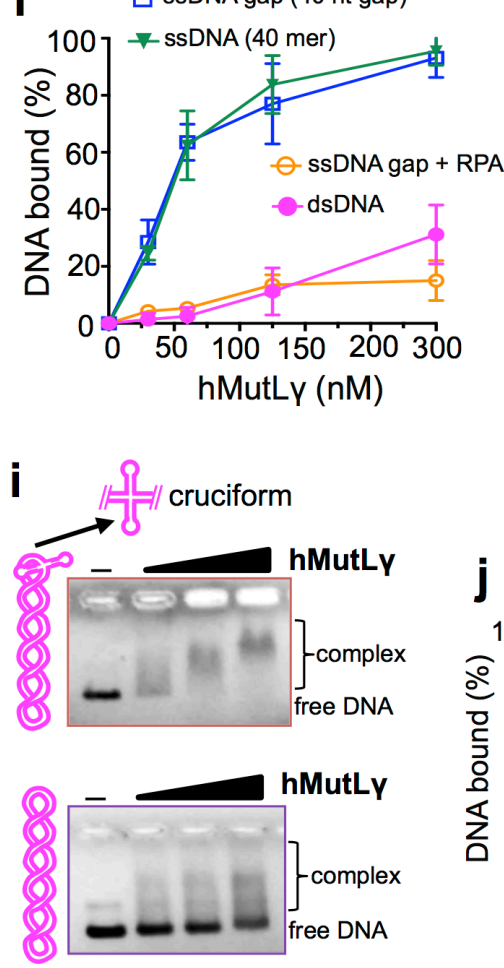
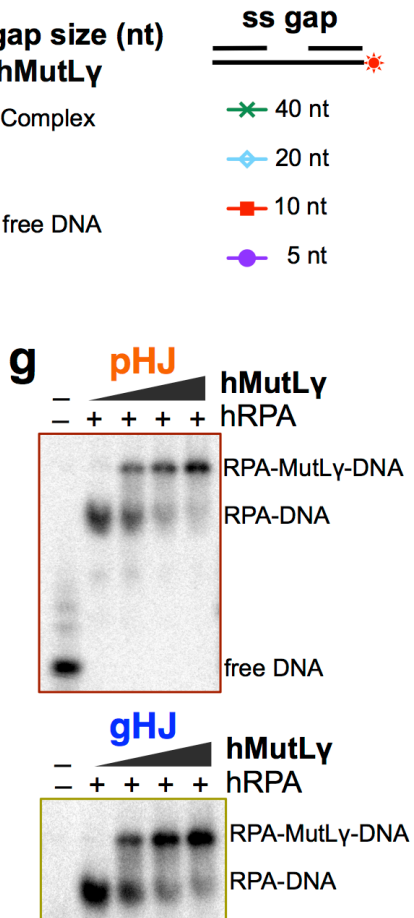

$-5 \mathrm{nt}$
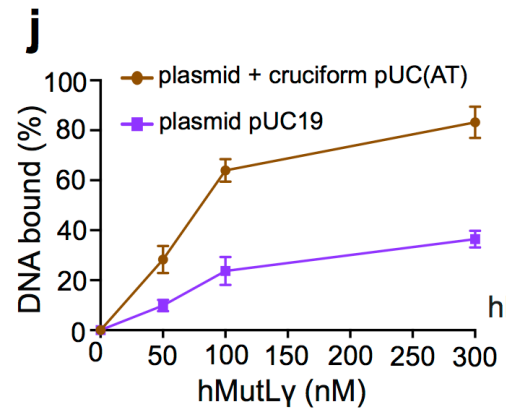

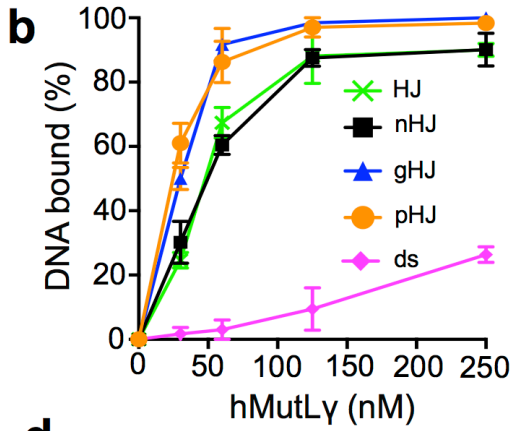

d
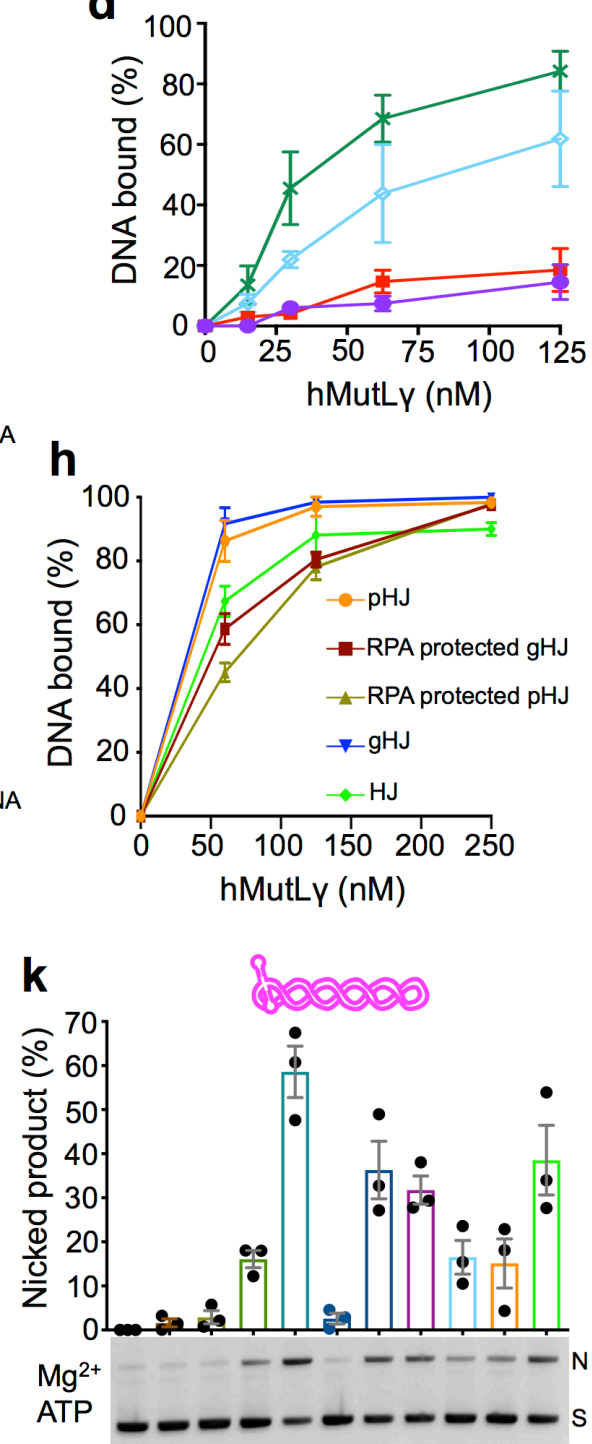

hPCNA ---++++++

hRFC ---++++++

hEXO1-D173A --++++-++-

hMutSy -++++-+++-

hMutly -++++-++++

$\begin{array}{llllllllllll}\text { lane } & 1 & 2 & 3 & 4 & 5 & 6 & 7 & 8 & 9 & 10 & 11\end{array}$ 
Figure 4. Holliday junctions are specifically bound by hMutLy and enhance its

endonuclease activity. a, Representative images of electrophoretic mobility shift assays

(EMSAs) analyzing hMutLy binding to control double-stranded DNA and the illustrated branched

DNA structures. Terminally ${ }^{32} \mathrm{P}$-labeled strands are indicated by asterisks. b, Quantification of the EMSAs represented in panel a showing means \pm SEM for three independent experiments.

c, Representative images of EMSAs analyzing hMutLy binding to 80mer DNAs containing single-strand gaps of varying size. d, Quantification of the EMSAs represented in panel c showing means \pm SEM for three independent experiments. e, Representative images of EMSAs for hMutLy binding to an 80mer DNA containing a 40 nucleotide gap, with or without prior incubation with RPA. f, Quantification of the EMSAs represented in panel e and Extended Data Fig. 5 shows that hMutLy binds a 40 nt gap with almost identical affinity as a 40 mer single stranded DNA; and that pre-incubation with RPA blocks hMutLy binding. Error bars show means \pm SEM for three independent experiments. g, Representative images of EMSAs for hMutLy binding to pro-HJs and gapped-HJs that were pre-incubated with RPA. h, Quantification of the EMSAs represented in panels a and $\mathbf{g}$. Error bars show means \pm SEM for three independent experiments. i, Representative images of EMSAs for hMutLy binding to pUC(AT) and pUC19 supercoiled plasmid substrates. j, Quantification of the EMSAs represented in panel i. Error bars show means \pm SEM for three independent experiments. $\mathbf{k}$, Representative gel image and quantification of ensemble endonuclease reactions with using pUC(AT) as substrate and $\mathrm{Mg}^{2+}$ as the sole metal cofactor. Reactions contained $25 \mathrm{nM}$ indicated proteins, $0.5 \mathrm{mM}$ ATP and 5 $\mathrm{mM} \mathrm{Mg}^{2+}$ and were incubated at $37^{\circ} \mathrm{C}$ for $30 \mathrm{~min}$. Means $\pm \mathrm{SEM}$ are shown for three experiments. 
a

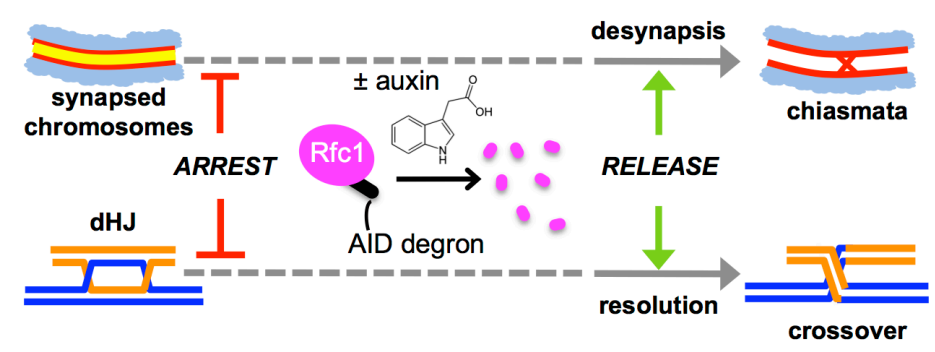

b
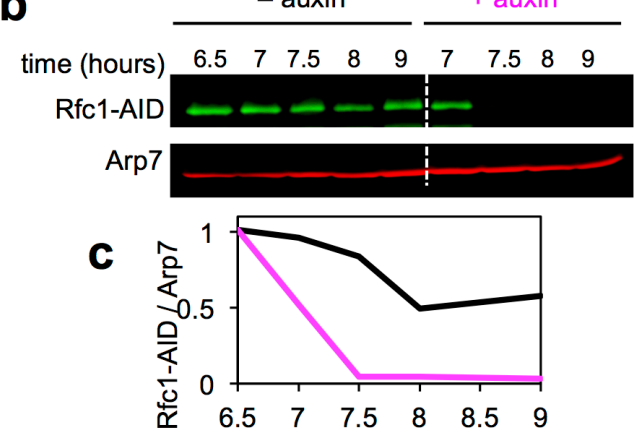

Time (hrs)

e
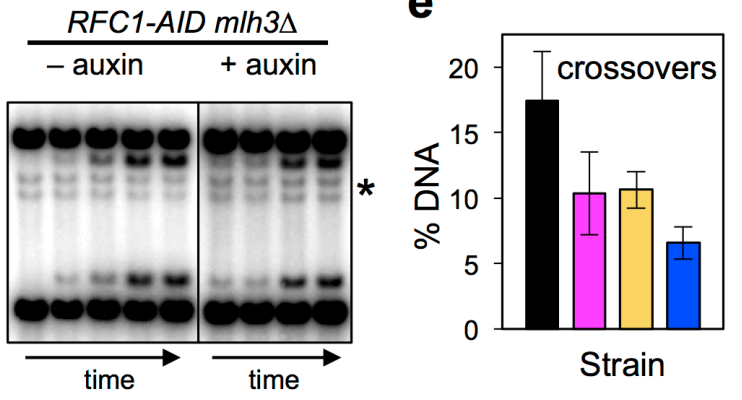

f

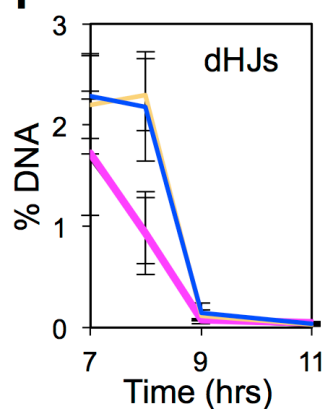

$\mathbf{g}$
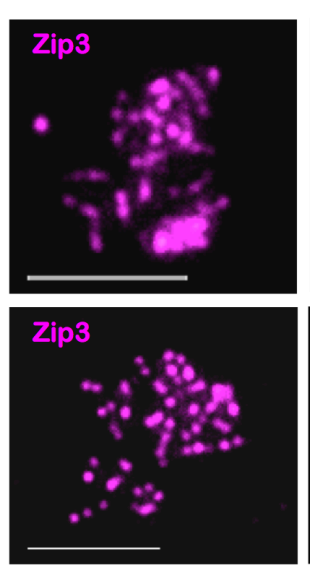
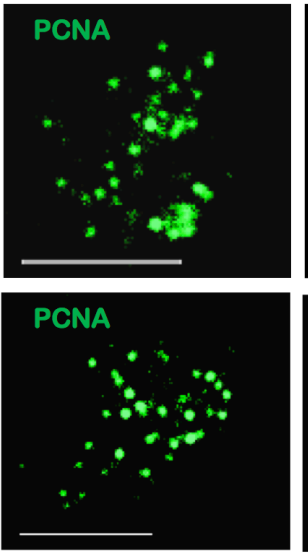
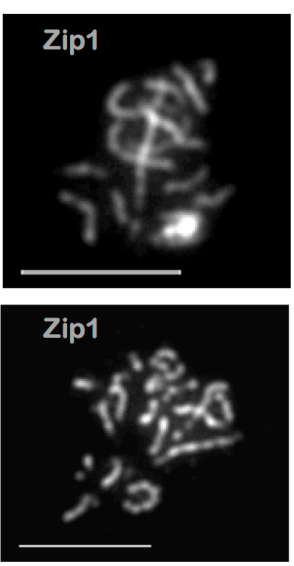
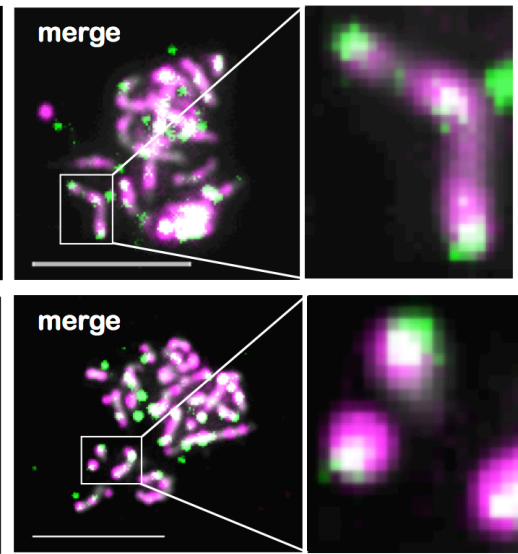

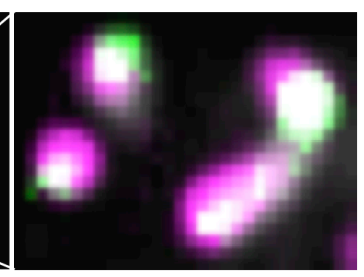

h
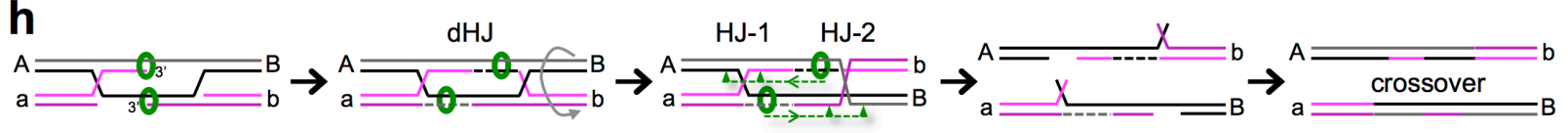

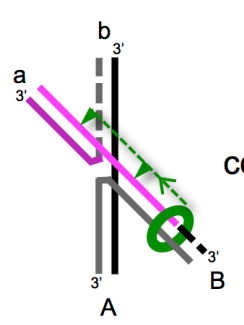

not resolved
$\mathrm{HJ}-1$

stacked conformers

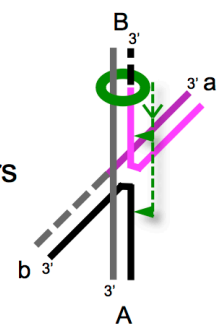

non-crossover

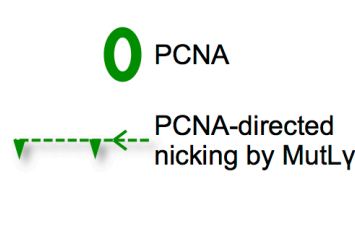

PCNA-directed nicking by MutLY

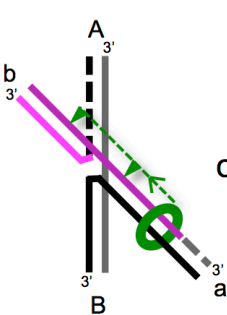

not resolved

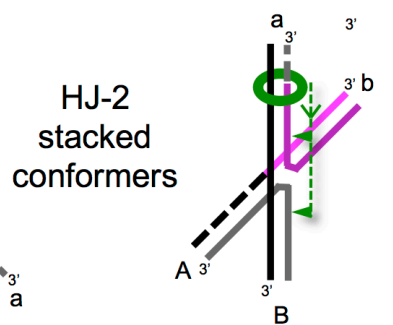

crossover 
Figure 5. RFC-PCNA promotes crossing over in vivo. a, Regimen to degrade RfC1-AID during the late stages of meiotic prophase. b, Western image showing Rfc1-AID levels in cells with and without the addition of auxin. c, Quantification of Rfc1-AID protein levels relative to ab Arp7 loading control. d, Representative Southern blot images of crossover analysis at the HIS4::LEU2 recombination hotspot. Time points are $0,7,8,9$, and 11 hours after induction of meiosis. e,f, Quantification of crossovers products and double Holliday junction $(\mathrm{dHJ})$ intermediates. "\% DNA" is percentage of total hybridizing DNA signal on 1D Southern blots, with error bars representing means \pm SEM. g, Representative images of surface spread meiotic nuclei immunostained for PCNA (green), the crossover marker Zip3 (magenta), and synaptonemal complex protein Zip1 (grey). Scale bars $=5 \mu \mathrm{m}$. PCNA and Zip3 foci were quantified in nuclei with pachytene morphologies (fully synapsed chromosomes indicated by linear Zip1 staining). Magnified panels show individual synaptonemal complexes with colocalizing PCNA and Zip3 signals. h, Model of crossover-specific dHJ resolution during meiosis. Top row: the orientations of PCNA molecules loaded during $\mathrm{dHJ}$ maturation direct MutLy to catalyze strand-specific nicking on either side of the two HJs. This pattern of incisions, in combination with migration about the junctions, results in crossover-specific resolution.

Bottom row: PCNA-directed MutLy incision results in resolution for only one of the two stacked$\mathrm{X}$ HJ conformers, which may be favored by factors such as MutSy. Alternatively, conformers may freely interconvert. For $\mathrm{HJ}-1$, resolution always produces a non-crossover; while for $\mathrm{HJ}-2$, crossover products are always formed. See text for further details.

\section{Methods}

\section{Purification hMutLy}

MBP-hMLH3-His ${ }^{10}$ and untagged hMLH1 ${ }^{19}$ were co-expressed in insect cells according to standard protocols (Bac-to-Bac system, Invitrogen) and hMutLy was purified as described by Ranjha et al. ${ }^{10}$ with the following modifications. Spodoptera frugiperda Sf9 cells were coinfected 
with optimized ratios of baculoviruses, cells were harvested $52 \mathrm{~h}$ after infection, washed with phosphate-buffered saline (PBS), frozen in liquid nitrogen and stored at $-80^{\circ} \mathrm{C}$. A typical purification was performed with cell pellets from 3.6 $\mathrm{L}$ of culture. All subsequent steps were carried out at $<4^{\circ} \mathrm{C}$. Cells were resuspended in 3 volumes of lysis buffer (50 mM HEPES-NaOH pH 7.4, 1 mM DTT, 1 mM EDTA, 1:500 (v/v) protease inhibitor cocktail (P8340 Sigma), 1 mM phenylmethylsulfonyl fluoride, $30 \mu \mathrm{g} / \mathrm{ml}$ leupeptin) and stirred slowly for $15 \mathrm{~min}$. Glycerol was added to $16 \%$ and $5 \mathrm{M} \mathrm{NaCl}$ was added for an final concentration of $325 \mathrm{mM}$. The sample was stirred for $30 \mathrm{~min}$ and then centrifuged at $50,000 \mathrm{~g}$ for $30 \mathrm{~min}$. The clarified extract was bound in batch mode to $8 \mathrm{ml}$ of pre-equilibrated amylose resin (New England Biolabs) for $1 \mathrm{hr}$. The resin was then washed extensively with $300 \mathrm{ml}$ of buffer a buffer comprising $50 \mathrm{mM}$ HEPES-NaOH pH 7.4, 2 mM $\beta$-mercaptoethanol, $250 \mathrm{mM} \mathrm{NaCl}, 10 \%$ glycerol, $1 \mathrm{mM}$ phenylmethylsulfonyl fluoride, $10 \mu \mathrm{g} / \mathrm{ml}$ leupeptin. Bound protein was eluted in wash buffer containing $10 \mathrm{mM}$ maltose. Next, the MBP tag was cleaved from MLH3 with PreScission protease at a 1:16 ratio of proteins for $1 \mathrm{hr}$. The sample was applied to a pre-equilibrated $1 \mathrm{ml}$ nickel-nitrilotriacetic acid resin column (Ni-NTA, Qiagen) over a 45 min period in wash buffer supplemented with $20 \mathrm{mM}$ imidazole. The column was then washed under gravity flow with $100 \mathrm{ml}$ buffer containing $60 \mathrm{mM}$ imidazole, before eluting bound protein with the same wash buffer containing $400 \mathrm{mM}$ imidazole. Pooled fractions were dialyzed against a buffer containing $25 \mathrm{mM}$ HEPES-NaOH pH 7.4, $1 \mathrm{mM}$ DTT $150 \mathrm{mM} \mathrm{NaCl}, 20 \%$ glycerol, $0.5 \mathrm{mM}$ phenylmethylsulfonyl, concentrated with $50 \mathrm{kDa}$ cut-off Amicon centrifugal filters (Millipore), and stored at 4 or $80^{\circ} \mathrm{C}$. Nuclease deficient hMutLy (containing hMLH3-D1223N) was created by using a QuikChange II Site-Directed Mutagenesis Kit (Agilent Technologies Inc, 200524). hMutLy containing hMLH3-D1223N protein was prepared in the same way as wild-type protein. Protein concentrations were determined by Bradford assay using Bovine serum albumin as a standard, and by spectroscopic absorption at $280 \mathrm{~nm}$. 


\section{Purification of hMutSy}

hMSH4 and hMSH5-6His coding regions were synthesized (GeneCopoeia), digested with Smal and Kpnl (for MSH4) or Sall and Xbal (for MSH5-6His) and cloned into the pFastBac Dual vector (ThermoFisher). Baculoviruses were prepared according to manufacturer's instructions and hMutSy was purified as described previously ${ }^{40}$. Insect cells were infected with $\mathrm{hMSH} 4 / \mathrm{hMSH} 5-6 \mathrm{His}$ baculovirus at $1 \times 10^{6}$ per $\mathrm{mL}$, and incubated at $27^{\circ} \mathrm{C}$ for $56 \mathrm{hrs}$ with shaking. Cells were centrifuged at $2000 \mathrm{rpm}$ for 10 minutes at $4^{\circ} \mathrm{C}$, washed with ice cold PBS, frozen in liquid nitrogen and stored at $-80^{\circ} \mathrm{C}$. A typical purification was performed with cell pellets from $1.6 \mathrm{~L}$ of culture. All subsequent steps were carried out at $<4^{\circ} \mathrm{C}$. Cells were thawed on ice-cold water for 5 min and then resuspended in 4 volumes of lysis buffer ( $25 \mathrm{mM}$ HEPES pH 8.1, 300 mM NaCl, 20 mM imidazole, 10\% glycerol, 500 uM PMSF, 10 mg/mL Pepstatin (Sigma), $10 \mu \mathrm{g} / \mathrm{mL}$ Leupeptin (Sigma), $10 \mu \mathrm{g} / \mathrm{mL}$ Aprotinin (Sigma), $1 \mu \mathrm{g} / \mathrm{ml}$ E-64 (Sigma) and lysate was passed five times through a $25 \mathrm{G}$ needle. The lysate was centrifuged at 35,000 rpm for 1 hour at $4^{\circ} \mathrm{C}$, and clarified extract was loaded onto a $5 \mathrm{ml}$ Ni-NTA column (GE Healthcare) pre-equilibrated with Buffer A (25 mM HEPES-NaOH pH 8.1, 300 mM NaCl, 20 mM Imidazole, 10\% glycerol containing $500 \mu \mathrm{M}$ PMSF, $1 \mu \mathrm{g} / \mathrm{mL}$ Pepstatin, and $1 \mu \mathrm{g} / \mathrm{mL}$ Leupeptin). The column was washed with 20 column volumes of Buffer A and then protein was eluted with a linear gradient of imidazole $(20-300 \mathrm{mM})$ in Buffer A. Peak fraction were pooled and applied to PBE-94 (Pharmacia) and Heparin Sepharose (GE Healthcare) columns in series. PBE/Heparin flow through was dialyzed against Buffer B (HEPES-NaOH pH 7.8, 100 mM NaCl, 1 mM DTT, $0.1 \mathrm{mM}$ EDTA, and 10\% glycerol, containing $500 \mu \mathrm{M}$ PMSF, $1 \mu \mathrm{g} / \mathrm{mL}$ Pepstatin, and $1 \mu \mathrm{g} / \mathrm{mL}$ Leupeptin). The protein was then loaded onto a $1 \mathrm{ml}$ Heparin-Sepharose column (GE Healthcare) pre-equilibrated with Buffer $\mathrm{B}$ and eluted with a linear gradient of $\mathrm{NaCl}$ (100 mM to $1 \mathrm{M}$ ). Peak fractions containing hMutSy were pooled and dialyzed against Buffer C (25 mM HEPES-NaOH pH 7.8, $100 \mathrm{mM} \mathrm{NaCl}, 1 \mathrm{mM}$ DTT, $0.1 \mathrm{mM}$ EDTA, 20\% glycerol) and 
concentrated with $50 \mathrm{kDa}$ cut-off Amicon centrifugal filters (Millipore). Aliquots were frozen in liquid nitrogen and stored at $-80^{\circ} \mathrm{C}$. Protein concentation was determined as described above.

\section{Purification of hEX01-D173A}

hEXO1 (D173A) was prepared as described previously ${ }^{19,40}$. Sf9 insect cells were infected with baculovirus expressing hEXO1-D173A at $1 \times 10^{6}$ per $\mathrm{mL}$ and incubated at $27^{\circ} \mathrm{C}$ for $58 \mathrm{hrs}$. Cells were centrifuged at $2000 \mathrm{rpm}$ for 10 minutes at $4^{\circ} \mathrm{C}$, frozen in liquid nitrogen and stored at $80^{\circ} \mathrm{C}$. All subsequent steps were carried out at $<4^{\circ} \mathrm{C}$. Cells were thawed on ice-cold water for 5 min and then resuspended in 5 volumes of lysis buffer $\mathrm{A}\left(20 \mathrm{mM} \mathrm{KPO}_{4} \mathrm{pH} 7.5,150 \mathrm{mM} \mathrm{KCL}\right.$, 0.1 mM EDTA) with Protease inhibitors (500 uM PMSF, 1 ug/mL Pepstatin, $10 \mathrm{ug} / \mathrm{mL}$ Leupeptin, $10 \mathrm{ug} / \mathrm{mL}$ Aprotinin, $1 \mathrm{ug} / \mathrm{ml}$ E-64). The cells were lysed using a dounce homogenizer for 5 strokes followed by gentle mixing on ice and addition of $50 \%$ glycerol to a final concertation $10 \%$, and $2 \mathrm{M} \mathrm{KCl}$ for a final concentration $150 \mathrm{mM}$. The suspension was then incubated for an additional $15 \mathrm{~min}$ with gentle stirring. The extract was then clarified by centrifuged at 55,000 rpm for 30 min and loaded onto a 15-ml Q-Sepharose column (GE Healthcare), preequilibrated with Q-Sepharose buffer $\left(20 \mathrm{mM} \mathrm{KPO}_{4}, \mathrm{pH} 7.5,100 \mathrm{mM} \mathrm{KCl}, 0.1 \mathrm{mM}\right.$ EDTA, $10 \%$ glycerol containing the same protease inhibitors used in the lysis buffer). The column was washed with 10 column volumes of Q-Sepharose buffer and eluted with a 5-column gradient of $\mathrm{KCl}$ gradient (100-400 mM) supplemented with 1mM DTT. hEXO1-D173A peak fractions were pooled and diluted two-fold with buffer $\mathrm{B}\left(20 \mathrm{mM} \mathrm{KPO}_{4} \mathrm{pH} 7.5,150 \mathrm{mM} \mathrm{KCL}, 10 \%\right.$ glycerol $0.1 \mathrm{mM}$ EDTA,1 mM DTT 0.5 mM PMSF, 1 ug/mL Pepstatin, 1ug/mL Leupeptin, 1 ug $/ \mathrm{mL}$ Aprotinin) and fractionated on a $5 \mathrm{ml}$ Heparin column (GE Healthcare) pre-equilibrated with buffer $\mathrm{B}$. The column was washed with 20 column volumes of buffer B and eluted with a 10-column gradient of $\mathrm{KCl}(100-415 \mathrm{mM})$. Peak fraction were diluted to $150 \mathrm{mM} \mathrm{KCl}$ with buffer $\mathrm{B}$ and loaded onto a $1 \mathrm{ml}$ MonoS column (GE Healthcare) pre-quilibrated with Mono S Buffer $(20 \mathrm{mM} \mathrm{KPO}, \mathrm{pH} 7.5$, 150 mM KCL, 0.1 mM EDTA 10\% glycerol, 0.5 mM PMSF, 1 mM DTT, 1 ug/mL Pepstatin, 1 
$\mathrm{ug} / \mathrm{mL}$ Leupeptin, $1 \mathrm{ug} / \mathrm{mL}$ Aprotinin). Non-specifically bound protein was removed with Mono $\mathrm{S}$ Buffer and elution was performed with a 2-column volume linear $\mathrm{KCl}$ gradient (100-500 mM). hEXO1-D173A eluted at $\sim 300 \mathrm{mM} \mathrm{KCl}$ on both the Heparin and MonoS columns. Peak fractions were subjected to Gel filtration chromatography on a S200 column (GE Healthcare) using S200 Buffer (20 mM KPO 4 , pH 7.5, 300 mM KCL, 0.1 mM EDTA, 5\% Glycerol, 0.5 mM PMSF and 1 $\mathrm{ug} / \mathrm{mL}$ Leupeptin). Peak fractions were collected, supplemented with $20 \%$ glycerol and 1 mM DTT, flash-frozen in liquid nitrogen, and stored at $-80^{\circ} \mathrm{C}$.

\section{hPCNA and hRFC and hRPA}

Purified hPCNA, hRFC and hRPA were generous gifts of Paul Modrich (Duke University), Jerry Hurwitz (MSKCC), and Steve Kowalczykowski (UC Davis), respectively.

\section{DNA substrates}

All oligonucleotides were obtained from Integrated DNA Technologies. Sequences are listed in Table 1. Oligonucleotides were 5' end-labeled with [ $\gamma$-32P] ATP (PerkinElmer Life Sciences) using T4 polynucleotide kinase (New England Biolabs). Unincorporated nucleotide was removed using G-50 Micro Columns (GE Healthcare). Substrate DNAs were annealed by combining end-labeled oligonucleotide with a 2-fold molar excess of the unlabeled complementary oligos. The end-labeled DNA substrates were then gel purified. Negatively supercoiled pUC19 and pUC-AT plasmids (New England Biolabs) were prepared using standard protocols.

\section{Nicking endonuclease assays}

Endonuclease nicking assays were performed using 100 ng negatively supercoiled pUC19 or cruciform-containing pUC-AT plasmid DNA in $20 \mu \mathrm{l}$ reaction mixtures containing $25 \mathrm{mM}$ HEPES-NaOH pH 7.4, $50 \mathrm{mM} \mathrm{NaCl,} \mathrm{1mM} \mathrm{DTT,} 5 \%$ glycerol, $0.2 \mathrm{mg} / \mathrm{mL}$ bovine serum albumin 
(NEB), indicated concentrations of purified proteins, and $5 \mathrm{mM}$ metal cofactors $\left(\mathrm{MnCl}_{2}, \mathrm{MgCl}_{2}\right.$, $\mathrm{ZnCl}_{2}, \mathrm{CaCl}_{2}, \mathrm{NiCl}_{2}$, or $\mathrm{CoCl}_{2}$, SIGMA). Where indicated, 5mM ATP, ADP, AMP-PNP or ATP-y-S (Sigma) was added.

Reactions employing RFC-PCNA contained 25 mM HEPES-NaOH pH 7.4, 25 mM NaCl, $1 \mathrm{mM}$ DTT, $0.2 \mathrm{mg} / \mathrm{mL}$ bovine serum albumin BSA, $2 \%$ glycerol and $5 \mathrm{mM} \mathrm{Mg}{ }^{2+}$ or $\mathrm{Mn}^{2+} .25 \mathrm{nM}$ hRFC, hPCNA, hEX01-D173A, hMutLy and hMutSy and 0.5 mM ATP were added as indicated. Reactions were assembled on ice, incubated at $37^{\circ} \mathrm{C}$ for indicated times, and stopped and deproteinized by adding $4 \mu \mathrm{l}$ Stop buffer (200 mM EDTA and $2 \mathrm{mg} / \mathrm{ml}$ proteinase $\mathrm{K}, 2 \% \mathrm{SDS}$ ) and incubating for $20 \mathrm{~min}$ at $55^{\circ} \mathrm{C}$ ). Plasmid isoforms were separated by electrophoresis in $1 \%$ agarose gel on $1 \% \operatorname{TAE}(1.25 \mathrm{~V} / \mathrm{cm} \sim 2 \mathrm{hrs})$ and gels were stained with $0.5 \mu \mathrm{g} / \mathrm{ml}$ ethidium bromide. Gel images were acquired with a Fluro Chem 8900 (Alpha Innotech) and quantified using Image J.

\section{EMSA DNA binding assay}

Indicated concentrations of hMutLy and $1 \mathrm{nM}$ of ${ }^{32} \mathrm{P}$-labeled DNA substrate were incubated in a $10 \mu$ reaction mixture containing $25 \mathrm{mM}$ HEPES $(\mathrm{pH} 7.8), 100 \mathrm{mM} \mathrm{NaCl}, 5 \mathrm{mM} \mathrm{MgCl}, 5 \%$ glycerol, $0.1 \mathrm{mg} / \mathrm{ml}$ BSA, $2 \mathrm{ng} / \mathrm{\mu l}$ poly $(\mathrm{dl} / \mathrm{dC})$ (SIGMA) and $1 \mathrm{mM}$ DTT supplemented with indicated concentrations of nucleotides and/or divalent metal ions. Reaction mixtures were assembled on ice and incubated at $4^{\circ} \mathrm{C}$ for $10 \mathrm{~min}$. To assemble hRPA coated ssDNA substrates, $1 \mathrm{nM}$ of ${ }^{32} \mathrm{P}$-labeled DNA substrates were combined in the reaction buffer described above together with indicated concentrations of hRPA and pre-incubated for $10 \mathrm{~min}$ at $4^{\circ} \mathrm{C}$ before adding hMutLy and incubating for an additional $10 \mathrm{~min}$. Bound and free DNA species were resolved by electrophoresis using non-denaturing $5 \%$ polyacrylamide gels in TAE buffer. Gels were dried on DE81 paper (Whatman) exposed to storage phosphor-storage screens and imaged using a Typhoon FLA 9000 imager (GE Healthcare). Fractions of mobility-shifted substrate were quantified, plotted and analyzed using Image $\mathrm{J}$ and GraphPad Prism software. 


$$
Y=\frac{\left(K_{D}+[D N A]+[M L H]-\sqrt{\left(K_{D}+[D N A]+[M L H)^{2}-4 *[D N A] *[M L H]\right.}\right.}{2 *[D N A]}
$$

The apparent equilibrium binding constants were obtained by fitting the data to the $1: 1$ binding equation, above, where $K_{\mathrm{D}}$ is the equilibrium dissociation constant, [DNA] is the concentration of DNA substrate $(1 \mathrm{nM})$ and $[\mathrm{MLH}]$ is concentration of hMutLY.

\section{Denaturing urea PAGE analysis of $\mathrm{HJ}$ endonuclease reactions}

Nuclease assays with $1 \mathrm{nM}$ labeled $\mathrm{HJ}$ or $\mathrm{nHJ}$ substrates were performed in $15 \mu$ volumes in presence of $5 \mathrm{mM} \mathrm{Mg}^{2+}$ and/or $\mathrm{Mn}^{2+}, 0.5 \mathrm{mM} \mathrm{ATP}$, and $25 \mathrm{nM}$ each protein in nuclease reaction buffer (above) for $30 \mathrm{~min}$ at $37^{\circ} \mathrm{C}$. Reactions were stopped by the addition of EDTA (50 mM) and Proteinase $\mathrm{K}$ treatment was performed for $15 \mathrm{~min}$ at $55^{\circ} \mathrm{C} .15 \mu \mathrm{l}$ formamide dye $(98 \%$ formamide, $10 \mathrm{mM}$ EDTA, $0.1 \%$ bromophenol blue and $0.1 \%$ and xylene cyanol) was added and reactions were denatured at $95^{\circ} \mathrm{C}$ for $5 \mathrm{~min}$. The denatured products were separated on $15 \%$ denaturing polyacrylamide gel (National diagnostic lab Urea PAGE system) in 1X TBE buffer. The gels were rinsed twice in a solution containing $40 \%$ methanol, $10 \%$ acetic acid, and $5 \%$ glycerol, and then fixed in the same solution for $30 \mathrm{~min}$ at room temperature. Gels were then vacuum dried on $3 \mathrm{~mm}$ Chr Whatman paper, exposed to storage phosphor screen and scanned using a Typhoon Phosphor imager (FLA 9000, GE Healthcare).

\section{Analysis of hMutL $\gamma-\mathrm{hPCNA}$ interaction}

$0.6 \mu \mathrm{g}$ anti-PCNA antibody (Santa Cruz Biotechnology F2, 25280) was incubated with $20 \mu \mathrm{l}$ Protein A beads and equilibrated in PBS buffer at $4^{\circ} \mathrm{C}$ for $2 \mathrm{hr}$ with gentle mixing. The beads were washed twice with $100 \mu \mathrm{PBS}$, mixed with $1 \mu \mathrm{g}$ recombinant hPCNA and $0.5 \mu \mathrm{g}$ hMutL $\gamma$ in $100 \mu$ l binding buffer (20 mM HEPES pH7.4, 50 mM NaCl, 5\% glycerol, 0.1 mM EDTA, 1 mM DTT), and incubated overnight at $4^{\circ} \mathrm{C}$ with gentle mixing. Supernatant was collected as 
unbound protein following a gentle spin at $1000 \mathrm{rpm}$ for $2 \mathrm{~min}$. Beads were washed three times with binding buffer (20 mM HEPES 7.4, $50 \mathrm{mM} \mathrm{NaCl}, 5 \%$ Glycerol, $0.1 \mathrm{mM}$ EDTA, $1 \mathrm{mM}$ DTT). The bound protein complexes were eluted in Laemmli buffer for $3 \mathrm{~min}$ at $95^{\circ} \mathrm{C}$ and separated on a 10\% SDS-PAGE gel. The gel was rinsed with water, stained with SYPRO-Ruby (Lonza50562) according to manufacturers recommendations, and imaged using a Typhoon FLA 9000 imager (GE Healthcare).

\section{Mice}

Mice were congenic with the C57BL/6J background and maintained and used for experiments according to the guidelines of Institutional Animal Care and Use Committees of the University of California Davis.

\section{Mouse cytology}

Surface-spread chromosomes of mouse spermatocytes were prepared from 18 days postpartum male mice using the drying-down technique as previously described ${ }^{41}$. Immunostaining was performed as previously described ${ }^{41}$ using the following primary and secondary antibodies: goat anti-SYCP3 (Santa Cruz Biotechnology, sc-20845; 1:200), rabbit anti-MSH4 (a gift from Dr. Paula Cohen; 1:200), mouse monoclonal anti-MLH1 (4C9C7) (Cell Signaling Technology, 3515S; 1:30), AMCA anti-goat (Jackson ImmunoResearch, 705-155-147; 1:50), Cy3 anti-rabbit (Jackson ImmunoResearch, 711-165-152; 1:100), and AlexaFluor647 antimouse (Jackson ImmunoResearch, 715-605-151; 1:100).

\section{Image acquisition and analysis of mouse cytology}

Chromosome spreads were imaged using a Zeiss Axioplan II microscope equipped with a $63 \mathrm{x}$ Plan-Apochromat 1.4 NA objective, EXFO X-Cite metal halide light source, and a Hamamatsu ORCA-ER CCD camera. Images were processed and analyzed using Volocity software (Perkin 
Elmer). Focus counts and colocalization were determined manually. Early, mid and late pachytene stages were defined using standard criteria.

\section{Yeast strains}

Full genotypes of the Saccharomyces cerevisiae strains (SK1 background) used in this study are listed in Supplementary Table 2. Adaptation of the Auxin-Induced Degron (AID) system for use during meiosis has been described previously ${ }^{42,43}$. Fusion of a minimal $A I D$ cassette to RFC1 was constructed using plasmid pHyg-AID*-9Myc as a template for PCR-mediated allele replacement, as previously described ${ }^{36,44}$. The estrogen-inducible IN-NDT80 GAL4-ER system has been described ${ }^{35,36,45,46}$.

\section{Meiotic time courses and DNA physical assays}

Detailed protocols for meiotic time courses and DNA physical assays at the HIS4::LEU2 locus have been described ${ }^{47,48}$. Degradation of Rfc1-AID was performed as pachytene cells were released from $I N-N D T 80$ arrest as described previously ${ }^{43}$, with the following modifications: at 6.5 hours after induction of meiosis, $\mathrm{CuSO}_{4}\left(100 \mathrm{mM}\right.$ stock in $\left.\mathrm{dH}_{2} \mathrm{O}\right)$ was added for a final concentration of $50 \mu \mathrm{M}$ to induce expression of $P_{C U P 1}-$ OsTIR1. Then at 7 hours, auxin (3indoleacetic acid, Sigma 13750, 2 M stock in DMSO) was added to one subculture at a final concentration of $2 \mathrm{mM}$ to induce degradation of Rfc1-AID; and estradiol (5 mM stock, Sigma E2758 in ethanol) was added to both subcultures to induce IN-NDT80. At 7.5 hours, auxin was added again at $1 \mathrm{mM}$. Cell samples were collected to assay protein depletion, meiotic divisions, and recombination intermediates as described previously ${ }^{36}$.

\section{Western analysis}

Whole cell extracts were prepared using the TCA extraction method, essentially as described $^{43}$. Samples were analyzed by standard SDS-PAGE and Western blotting. Anti-c-myc 
monoclonal antibody (Roche; 11667149001) was diluted 1:1,000 to detect Rfc1-AID; Arp7 polyclonal antibody (Santa Cruz, SC-8961) was used at 1:5,000 dilution as a loading control. Secondary antibodies, used at 1:5,000 dilution, were IRDye® 800CW Donkey anti-Mouse IgG (LI-COR, 925-32212) and IRDye® 680LT Donkey anti-Goat IgG (LI-COR, 925-68024). Membranes were imaged with an Odyssey Infrared Imager (LI-COR). Quantification of protein bands was performed using Image Studio Lite 5.0.21 software.

\section{Yeast cytology and chromosome spreading}

Meiotic cells were collected at indicated time points and fixation and chromosome spread was performed as described using $4 \%$ paraformaldeyde ${ }^{49}$. Immunostaining was performed as described $^{49}$. Primary antibodies were anti-PCNA (Abcam; ab70472, 1:100), anti-Zip3 antibody (a gift from Dr. Akira Shinohara, 1:400) and anti-Zip1 (a gift from Dr. Scott Keeney, 1:400); all incubated overnight at room temperature in $100 \mathrm{ul} \mathrm{TBS/BSA} \mathrm{buffer} \mathrm{(10} \mathrm{mM} \mathrm{Tris} \mathrm{PH7.5,} 150 \mathrm{mM}$ $\mathrm{NaCl}, 1 \% \mathrm{BSA}$ ) Secondary antibodies were anti-rabbit 568 (A11036 Molecular Probes, 1:1000), anti-mouse 488 (A11029 Molecular Probes, 1:1000), anti-rabbit 647 (A21245 Invitrogen), and anti-guinea pig 555 (A21435 Life Technologies); all for $1 \mathrm{hr}$ at $37^{\circ} \mathrm{C}$. Coverslips were mounted with Prolong Gold antifade reagent (Invitrogen, P36930). Digital images were captured using a Zeiss Airyscan LSM800 with Axiocam and analyzed using Zen (blue edition); or a Zeiss Axioplan II microscope, Hamamatsu ORCA-ER CCD camera and analyzed using Volocity software. Co-localization of protein foci was assigned to overlapping foci. Scatterplots were generated using the GraphPad program in Prism.

40 Genschel, J., Bazemore, L. R. \& Modrich, P. Human exonuclease I is required for 5' and 3' mismatch repair. The Journal of biological chemistry 277, 13302-13311, doi:10.1074/jbc.M111854200 (2002). 
41 Kolas, N. K. et al. Localization of MMR proteins on meiotic chromosomes in mice indicates distinct functions during prophase I. The Journal of cell biology 171, 447-458 (2005).

42 Nishimura, K., Fukagawa, T., Takisawa, H., Kakimoto, T. \& Kanemaki, M. An auxinbased degron system for the rapid depletion of proteins in nonplant cells. Nature methods 6, 917-922, doi:10.1038/nmeth.1401 (2009).

43 Tang, S., Wu, M. K., Zhang, R. \& Hunter, N. Pervasive and essential roles of the Top3Rmi1 decatenase orchestrate recombination and facilitate chromosome segregation in meiosis. Mol Cell 57, 607-621, doi:10.1016/j.molcel.2015.01.021 (2015).

44 Morawska, M. \& Ulrich, H. D. An expanded tool kit for the auxin-inducible degron system in budding yeast. Yeast 30, 341-351, doi:10.1002/yea.2967 (2013).

45 Benjamin, K. R., Zhang, C., Shokat, K. M. \& Herskowitz, I. Control of landmark events in meiosis by the CDK Cdc28 and the meiosis-specific kinase Ime2. Genes \& development 17, 1524-1539, doi:10.1101/gad.1101503 (2003).

46 Louvion, J. F., Havaux-Copf, B. \& Picard, D. Fusion of GAL4-VP16 to a steroid-binding domain provides a tool for gratuitous induction of galactose-responsive genes in yeast. Gene 131, 129-134 (1993).

47 Owens, S., Tang, S. \& Hunter, N. Monitoring Recombination During Meiosis in Budding Yeast. Methods Enzymo/ 601, 275-307, doi:10.1016/bs.mie.2017.12.005 (2018).

48 Hunter, N., and Kleckner, N. The Single-End Invasion: An Asymmetric Intermediate at the Double-Strand Break to Double-Holliday Junction Transition of Meiotic Recombination. Cell 106, 59-70 (2001).

49 Grubb, J., Brown, M. S. \& Bishop, D. K. Surface Spreading and Immunostaining of Yeast Chromosomes. J Vis Exp, e53081, doi:10.3791/53081 (2015). 


\section{Acknowledgements}

We thank Paul Modrich (Duke), Jerry Hurwitz (MSKCC), Ken Marians (MSKCC), Steve Kowalczykowski (UCD) Paula Cohen (Cornell), Scott Keeney (MSKCC) and Akira Shinohara (Osaka University) for reagents; Petr Cejka (Università della Svizzera italiana) for reagents and communicating unpublished data; and members of the Hunter Lab for support and discussions. This work was supported by NIH NIGMS grant GM074223 to N.H. S.O. was supported by NIH NIGMS T32 Training Program in Molecular and Cellular Biology 5T32GM007377 and an F31

Ruth L. Kirschstein National Research Service Award 1F31GM125106. M.I. was supported by a Japan Society for the Promotion of Science postdoctoral fellowship for research abroad. N.H. is an Investigator of the Howard Hughes Medical Institute.

\section{Author Contributions}

D.S.K., S.O., M.H. and N.H. conceived the study and designed most experiments. All authors performed experiments and analyzed the data. D.S.K., S.O and N.H. wrote the manuscript with inputs and edits from all authors.

\section{Competing interests}

The authors declare no competing interests.

\section{Corresponding author}

Correspondence to Neil Hunter nhunter@ucdavis.edu

\section{Supplementary information}

This file contains Supplementary Tables 1 and 2 .

\section{Extended Data}




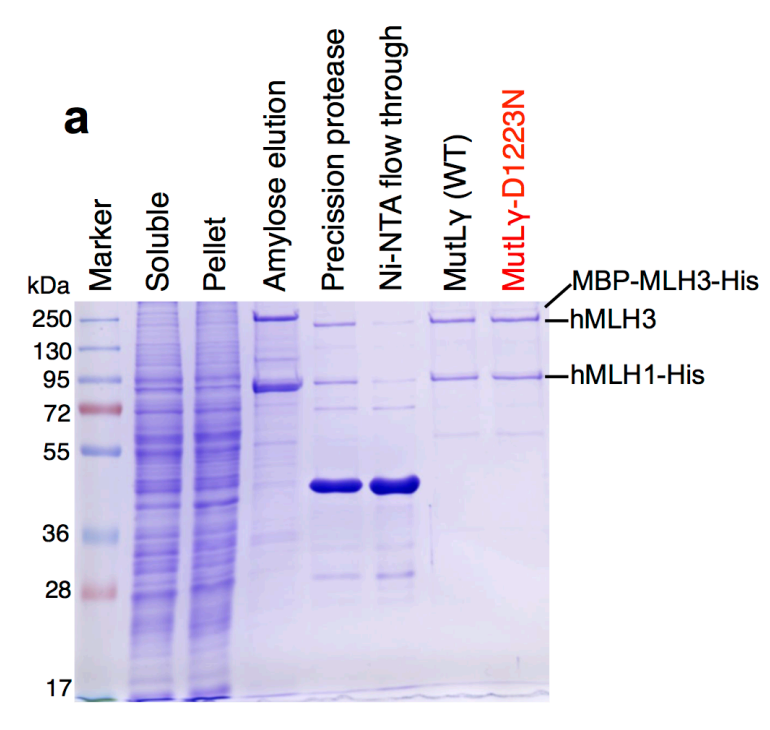

b
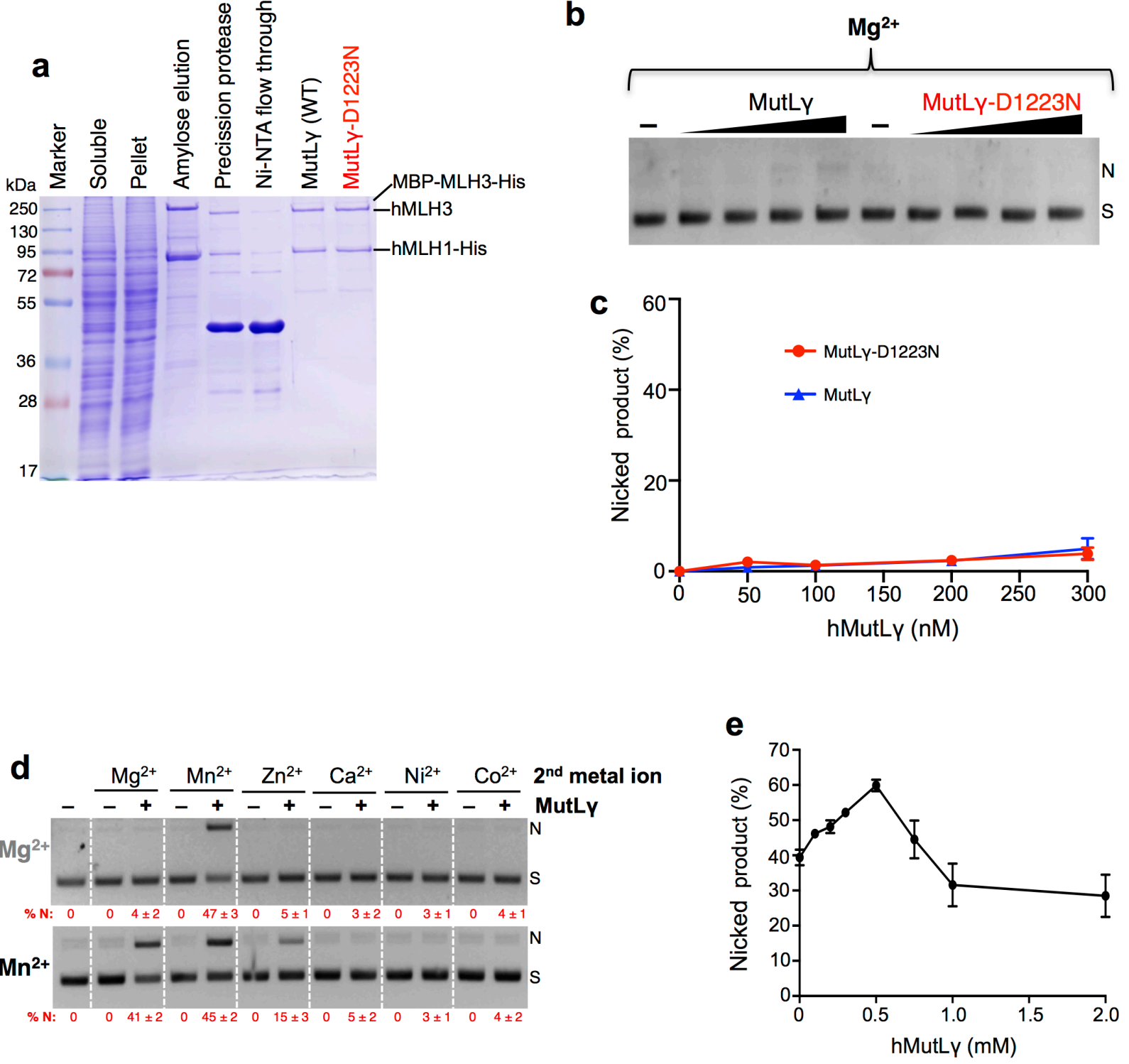

Extended Data Figure 1. Purification of human MutL $\gamma$ and characterization of

endonuclease experiment. a, Representative MutL $\gamma$ purification steps monitored by $10 \%$ SDS-

PAGE stained with Coomassie blue. Amylose enriched fractions were treated with Precission

Protease, to cleave the maltose-binding protein tag, and then subjected to Ni-NTA affinity

purification. b, Representative endonuclease assays for varying concentrations of hMutL $\gamma$ and

hMutL $\gamma-\mathrm{D} 1223 \mathrm{~N}\left(0-300 \mathrm{nM}\right.$ protein and $5 \mathrm{mM} \mathrm{Mg}^{2+}$ incubated at $37^{\circ} \mathrm{C}$ for $\left.60 \mathrm{~min}\right)$. Migration positions of supercoiled (S) plasmid and nicked (N) product are indicated. c, Quantitation of experiments represented in panel $\mathbf{b}$ shows that the hMutL $\gamma$ endonuclease is inactive in $\mathbf{M g}^{2+}$. 
Means \pm SEM are shown for three experiments. d, Representative endonuclease assays with $100 \mathrm{nM}$ hMutL $\gamma$ in $5 \mathrm{mM} \mathrm{Mg}^{2+}$ or $\mathrm{Mn}^{2+}$ with the addition of various second metal cofactors (5 $\mathrm{mM})$. Reactions were incubated at $37^{\circ} \mathrm{C}$ for $90 \mathrm{~min}$. Metals other than $\mathrm{Mg}^{2+}$ compete with $\mathrm{Mn}^{2+}$ to inhibit hMutL $\gamma$ endonuclease activity. $\% \mathrm{~N}$, percent nicked product. Means \pm SEM are shown for three experiments after subtracting background nicked product from no-protein controls. e, hMutLy endonuclease activity with increasing ATP concentration. $100 \mathrm{nM}$ hMutLy was incubated with $5 \mathrm{mM} \mathrm{Mn}^{2+}$ and indicated concentrations of ATP at $37^{\circ} \mathrm{C}$ for $60 \mathrm{~min}$. Endonuclease stimulation was optimal with $0.5 \mathrm{mM} \mathrm{ATP}$, while higher concentrations were inhibitory. 


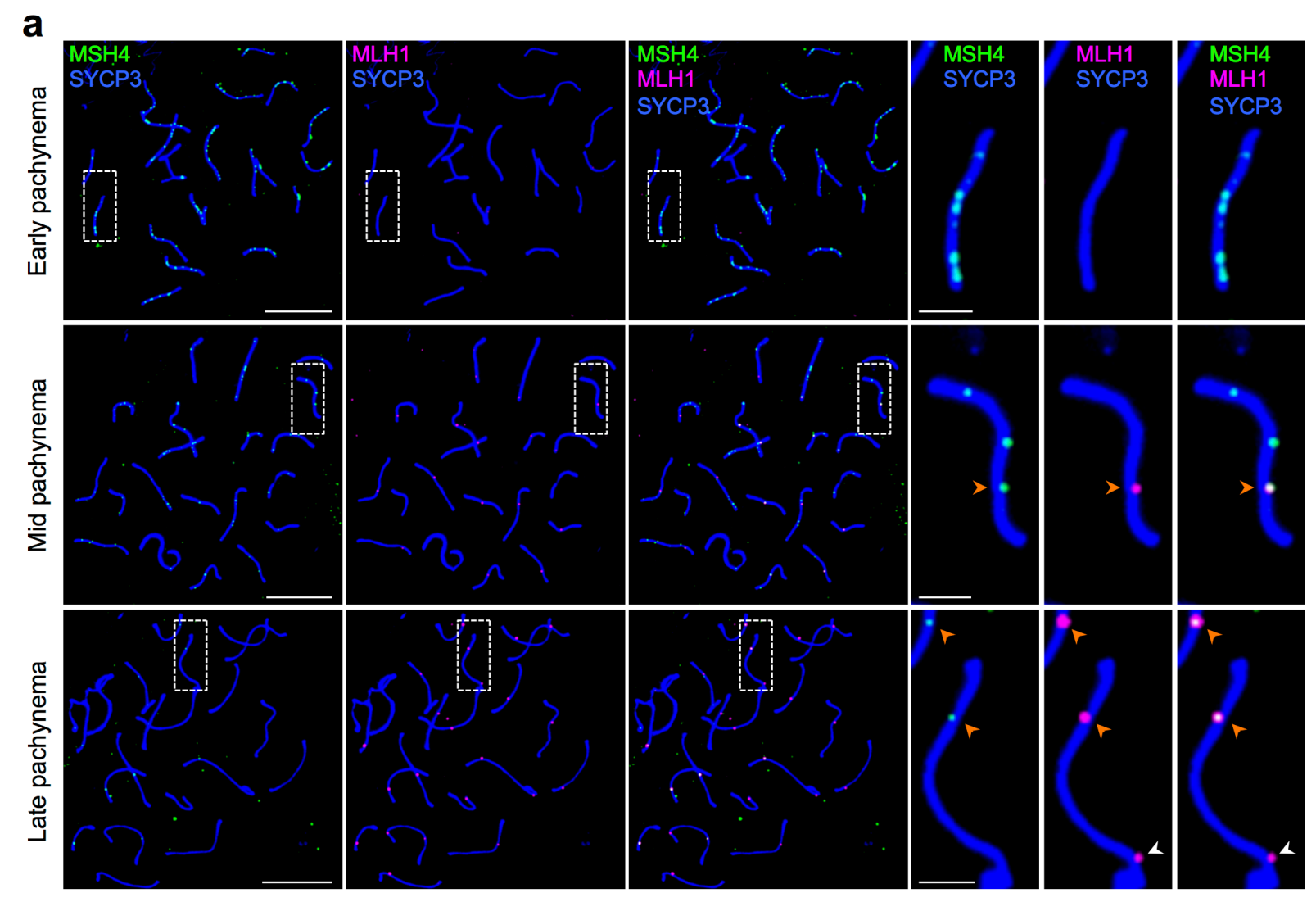

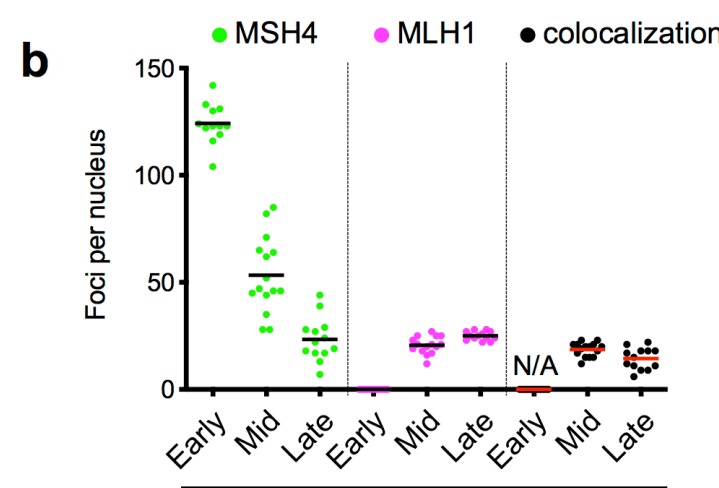

Pachytene sub stage

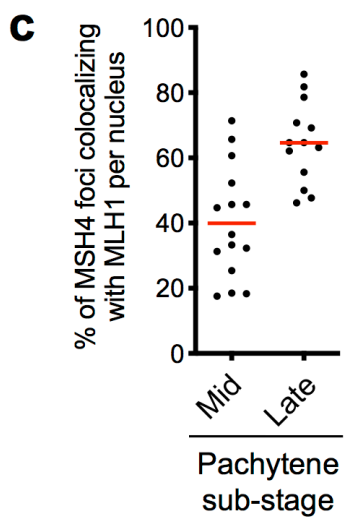

Extended Data Figure 2. Colocalization of MutL $\gamma$ and MutS $\gamma$ in mouse spermatocytes.

a, Representative images of surface-spread spermatocyte chromosomes from the indicated pachytene substages, immuno-stained for MSH4 (green), MLH1 (magenta) and the chromosome axis marker SYCP3 (blue). Magnified panels show individual pairs of synapsed chromosomes. Arrowheads indicate crossover-specific MLH1 foci that colocalize with MSH4. b, Quantification of MSH4 and MLH1 foci and MSH4-MLH1 cofoci in mid- and late-pachytene 
stages (N/A, not applicable because MLH1 foci were not observed in early pachytene). c, Percent of MSH4 foci that are colocalized with MLH1 in mid and late pachytene nuclei. The fraction of co-foci increases as the other MSH4 foci disappear in late pachynema.

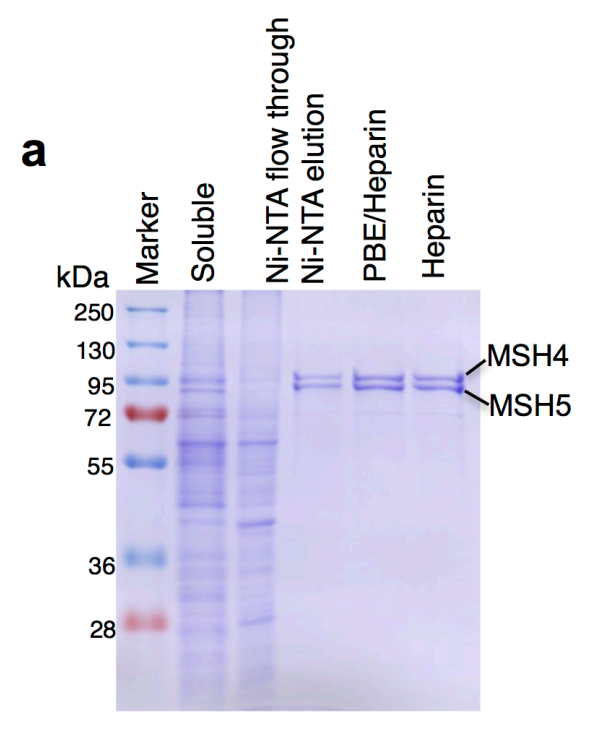

b

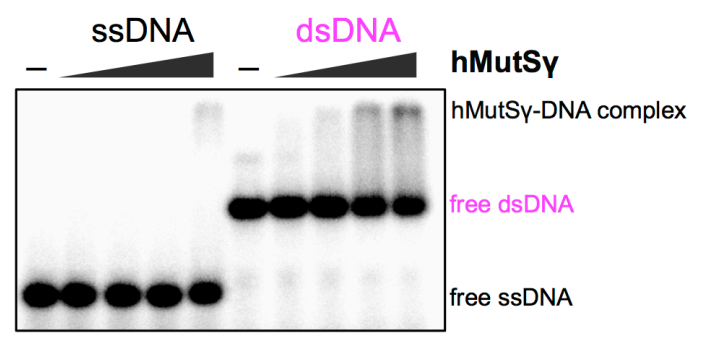

C

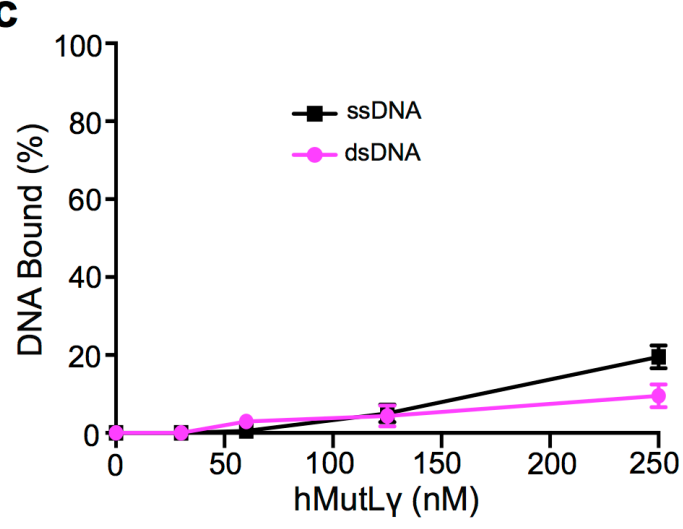

d

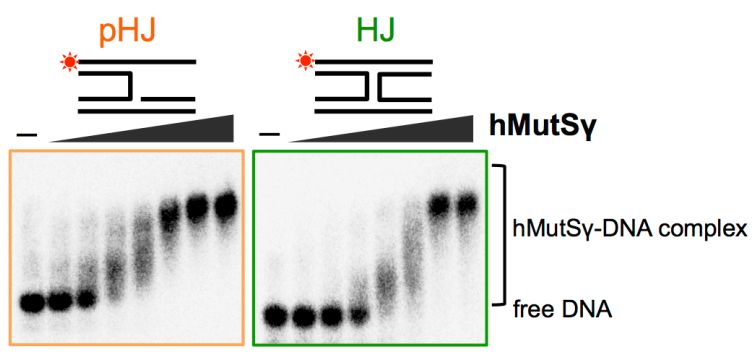

e

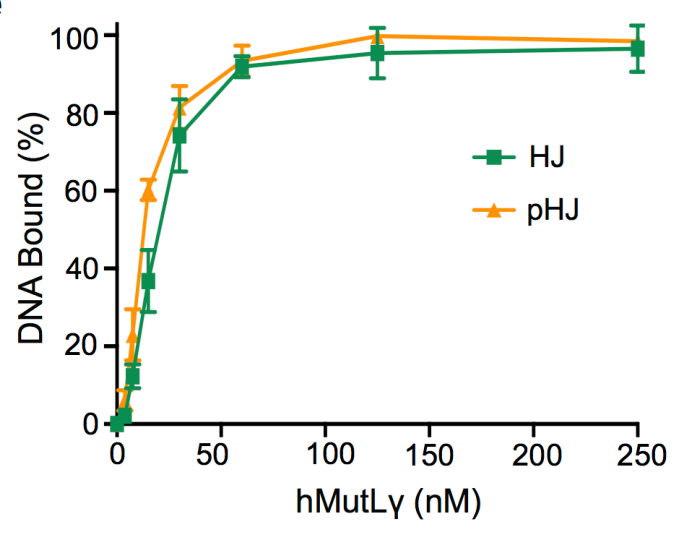

Extended Data Figure 3. Purification and characterization of human MutS $\gamma$. 
a, Representative hMutS $\gamma$ purification steps monitored by $10 \%$ SDS-PAGE stained with Coomassie blue. b, Representative images of electrophoretic mobility shift assays (EMSAs) analyzing hMutSy binding to 80mer single and double-stranded DNAs. c, Quantification of the EMSAs represented in panel $\mathbf{b}$ showing means \pm SEM for three independent experiments.

d, Representative images of EMSAs analyzing hMutSy binding to pro-HJ and Holliday junction structures. Terminally ${ }^{32} \mathrm{P}$-labeled strands are indicated by asterisks. e, Quantification of the EMSAs represented in panel $\mathbf{d}$ confirm high affinity binding of hMutSy to $\mathrm{pHJ}$ and $\mathrm{HJ}$ structures. In $\mathbf{c}$ and $\mathbf{e}$, means \pm SEM for three independent experiments. Binding reactions contained $5 \mathrm{nM}$ ${ }^{32} \mathrm{P}$-labeled DNA, $100 \mathrm{mM} \mathrm{NaCl}$ and $5 \mathrm{mM} \mathrm{Mg}^{2+}$ and were incubated on ice for $10 \mathrm{~min}$. Bound and free DNA species were resolved by non-denaturing $5 \%$ polyacrylamide gel electrophoresis and processed for imaging.

a

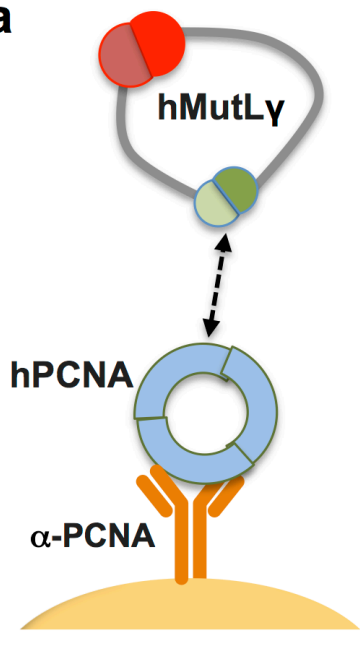

b

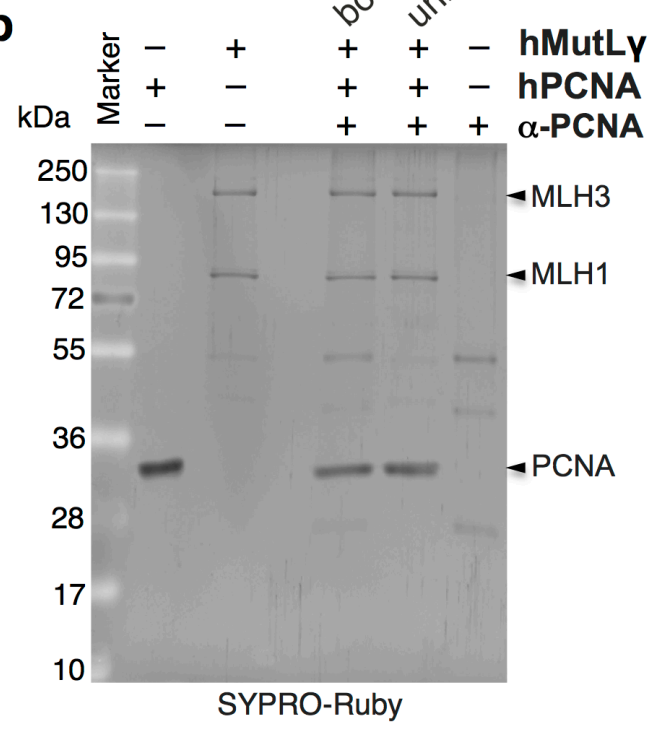

Extended Data Figure 4. hMutLy and hPCNA interact in solution. a, Experimental scheme to analyze hMutLy-hPCNA interaction in solution. b, SYPRO-Ruby stained SDS-PAGE analysis of hMutLy-hPCNA interaction. 

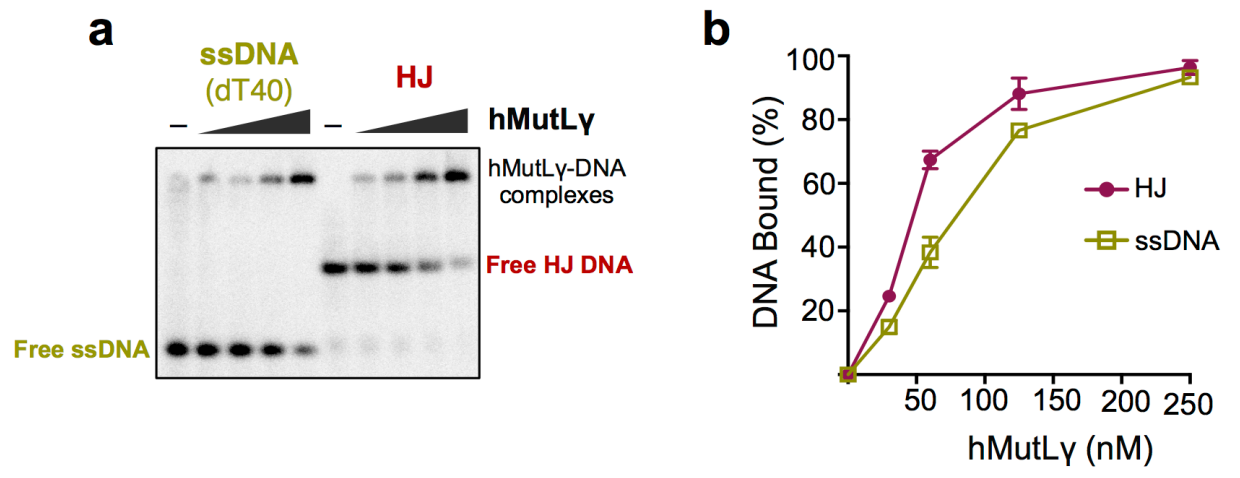

Extended Data Figure 5. ssDNA binding by hMutLy. a, Representative image of EMSAs comparing hMutLy binding to ssDNA and Holliday junctions.. b, Quantification of the EMSAs represented in panel a. Means \pm SEM for three independent experiments are shown. Binding reactions contained $1 \mathrm{nM}^{32} \mathrm{P}$-labeled DNA, $100 \mathrm{mM} \mathrm{NaCl}$ and $5 \mathrm{mM} \mathrm{Mg}^{2+}$ and were incubated on ice for $10 \mathrm{~min}$. Bound and free DNA species were resolved by non-denaturing $5 \%$ polyacrylamide gel electrophoresis and processed for imaging.

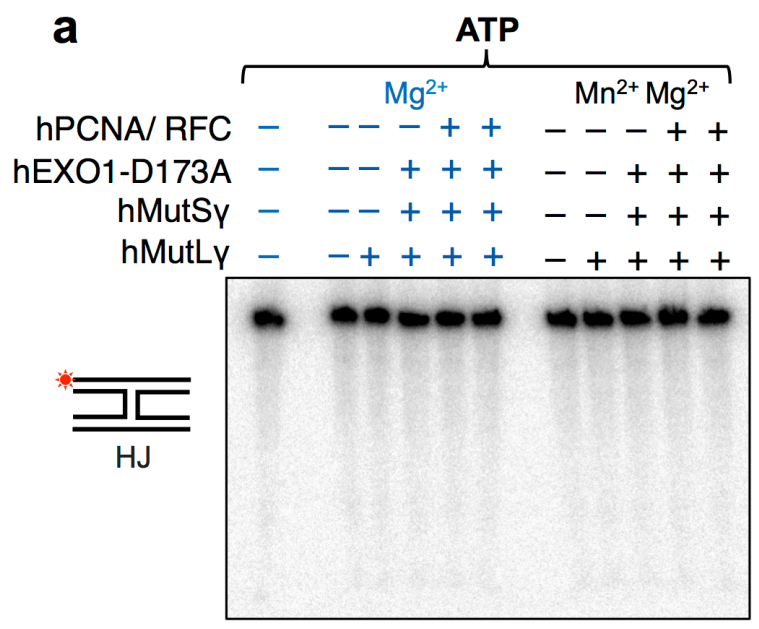

Denaturing Urea-PAGE

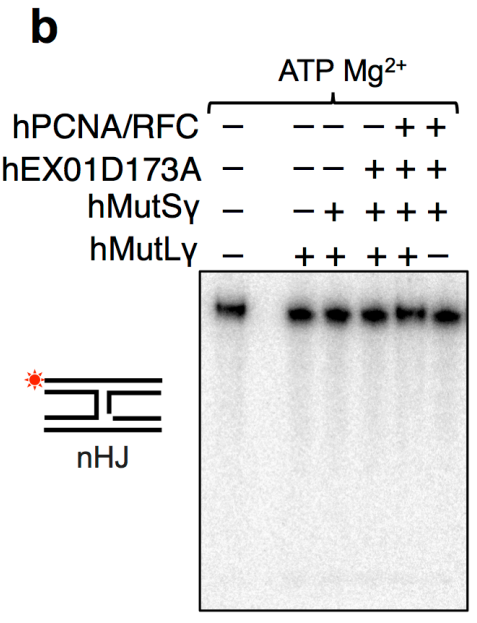

Denaturing Urea-PAGE

\section{Extended Data Figure 6. Model Holliday junctions are not incised by hMutLy.}

$\mathbf{a}$ and $\mathbf{b}$, Representative gel images of ensemble endonuclease reactions with $\mathrm{HJ}$ and nicked $\mathrm{HJ}$ substrates. Reactions contained $25 \mathrm{nM}$ indicated proteins, $0.5 \mathrm{mM} \mathrm{ATP}$ and $5 \mathrm{mM} \mathrm{Mg} \mathrm{Mgn}^{2+}$, and were incubated at $37^{\circ} \mathrm{C}$ for $30 \mathrm{~min}$. The reaction products were analyzed on a $15 \%$ denaturing polyacrylamide gel to detect nicking at any position. Nicked DNA strands were not 
detected and non-denaturing gels showed that model $\mathrm{HJ}$ s and $\mathrm{nHJs}$ were not resolved by the hMutLy ensemble (not shown).
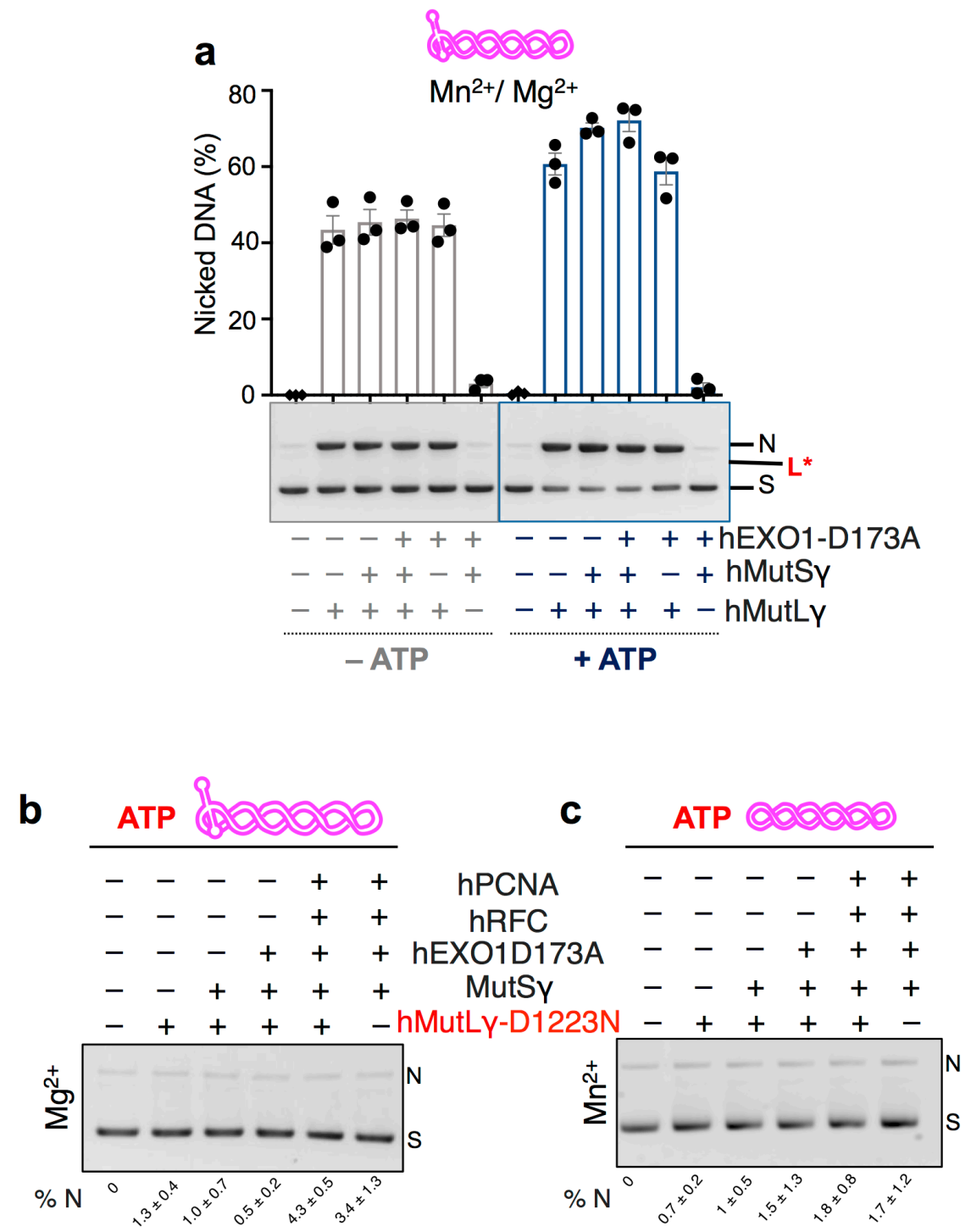

Extended Data Figure 7. Endonuclease assays the $\mathrm{HJ}$-containing pUC(AT) DNA substrate on hMutLy ensemble endonuclease reactions. a, Endonuclease assays with pUC(AT) and varying mixtures of hMutL $\gamma, \mathrm{hMutS} \gamma$ and hEXO1-D173A, with and without ATP (50 nM each protein, $0.5 \mathrm{mM} \mathrm{ATP}, 5 \mathrm{mM} \mathrm{Mn}^{2+}$ and $5 \mathrm{mM} \mathrm{Mg}^{2+}$, incubated at $37^{\circ} \mathrm{C}$ for $\left.60 \mathrm{~min}\right)$. Means $\pm \mathrm{SEM}$ are shown for three experiments. Under these conditions, pUC(AT) is incised 1.3-1.7-fold more efficiently than the corresponding reactions with pUC19 (see Fig. $\mathbf{2 g}$ ). Notably, the linear 
cleavage product $\left(\mathrm{L}^{*}\right)$ seen with pUC19 (Fig. $\mathbf{2 g}$ ) was not observed with pUC(AT). Thus, both the efficiency of nicking and the nature of the incision products are altered when a Holliday junction is present. $\mathbf{b}$ and $\mathbf{c}$, Negative control ensemble endonuclease assays for pUC(AT) (b) and pUC19 (c) containing nuclease-dead hMutL $\gamma$-D1223N. Reactions contained 25 nM indicated proteins, $0.5 \mathrm{mM} \mathrm{ATP}$ and $5 \mathrm{mM} \mathrm{Mg}^{2+}$ or $\mathrm{Mn}^{2+}$ and were incubated at $37^{\circ} \mathrm{C}$ for $30 \mathrm{~min}$. Average percent nicking $(\% \mathrm{~N}) \pm \mathrm{SEM}$ are shown for three experiments.

\section{b}
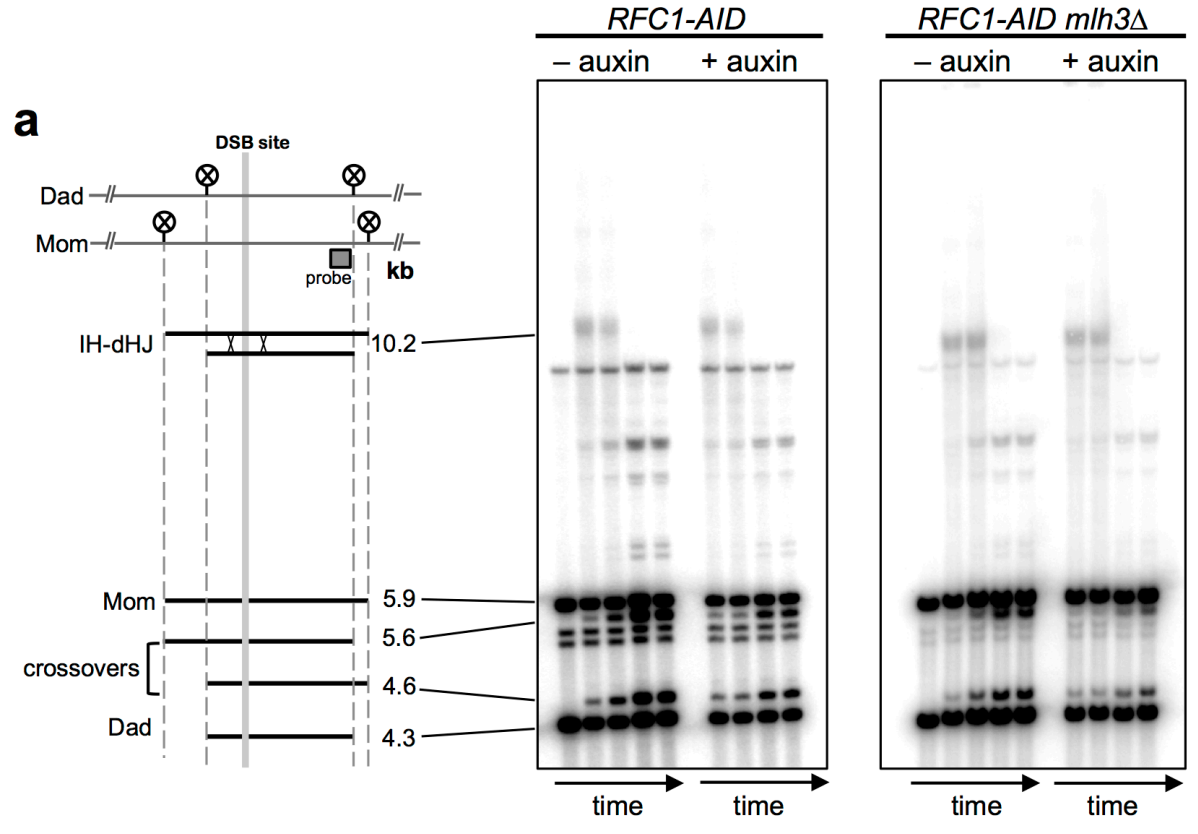

\section{Extended Data Figure 8. Physical assay system for analysis of meiotic recombination $\mathbf{n}$}

budding yeast. a, Map of the HIS4:LEU2 recombination hotspot locus highlighting the initiating DSB site, Xhol restriction sites (circled Xs) and the position of the probe used in Southern blotting. Sizes of diagnostic fragments are shown below. b, Representative 1D gel Southern blot images for analysis of crossovers and $\mathrm{dHJs}$ in RFC1-AID and RFC1-AID mlh3A strains, with and without the addition of auxin to trigger Rfc1-AID degradation. Time points are $0,7,8,9$, and 11 hours after induction of meiosis. 


\section{Supplementary Data}

\begin{tabular}{|c|c|}
\hline Name & Sequence (5' to $\left.3^{\prime}\right)$ \\
\hline$A X$ & $\begin{array}{l}\text { 5'-CTAGTATAGAGCCGGCGCGCCATGTCTAGATAGCGTTAGG- } \\
\text { TCTGCCGAATAGTACTACTCGGATCCCGAGCGAACCACGC-3' }\end{array}$ \\
\hline BS & $\begin{array}{l}\text { 5'-GCGTGGTTCGCTCGGGATCCGAGTAGTACTATTCGGCAGA- } \\
\text { GGATTCGAATAGGCCTAATCGAATTCCGCCATCGATGCAC-3' }\end{array}$ \\
\hline ES & $\begin{array}{l}\text { 5'-GTGCATCGATGGCGGAATTCGATTAGGCCTATTCGAATCC- } \\
\text { AGACGCGAGTAGATCTTCACGGTACCCGCGGTTACCCGTG-3' }\end{array}$ \\
\hline KB & $\begin{array}{l}\text { 5'-CACGGGTAACCGCGGGTACCGTGAAGATCTACTCGCGTCT- } \\
\text { CCTAACGCTATCTAGACATGGCGCGCCGGCTCTATACTAG-3' }\end{array}$ \\
\hline AXdT40 & $\begin{array}{l}\text { 5'-CTAGTATAGAGCCGGCGCGCCATGTCTAGATAGCGTTAGG- } \\
\text { TTTTTTTTTTTTTTTTTTTTTTTTTTTTTTTTTTTTTTTT-3' }\end{array}$ \\
\hline$A X-C$ & $\begin{array}{l}\text { 5'-GCGTGGTTCGCTCGGGATCCGAGTAGTACTATTCGGCAGA- } \\
\text { CCTAACGCTATCTAGACATGGCGCGCCGGCTCTATACTAG-3' }\end{array}$ \\
\hline 3BS & 5'-GGATTCGAATAGGCCTAATCGAATTCCGCCATCGATGCAC-3' \\
\hline KBG1 & 5'-CACGGGTAACCGCGGGTACCGTGAAGATCTACTCGCGTCTCCTAA-3' \\
\hline KBG2 & 5'-CCGGCTCTATACTAG-3' \\
\hline $3 \mathrm{~J}$ & $\begin{array}{l}\text { 5'-GCGTGGTTCGCTCGGGATCCGAGTAGTACTATTCGGCAGA- } \\
\text { AGACGCGAGTAGATCTTCACGGTACCCGCGGTTACCCGTG-3 }\end{array}$ \\
\hline 5BSdT40 & $\begin{array}{l}\text { 5'-GCGTGGTTCGCTCGGGATCCGAGTAGTACTATTCGGCAGA- } \\
\text { TTTTTTTTTTTTTTTTTTTTTTTTTTTTTTTTTTTTTTTT-3' }\end{array}$ \\
\hline 3KBdT40 & \begin{tabular}{|l} 
5'-TTTTTTTTTTTTTTTTTTTTTTTTTTTTTTTTTTTTTTTTT- \\
CCTAACGCTATCTAGACATGGCGCGCCGGCTCTATACTAG-3'
\end{tabular} \\
\hline $5 B S$ & 5'-GCGTGGTTCGCTCGGGATCCGAGTAGTACTATTCGGCAGA-3' \\
\hline $3 \mathrm{~KB}$ & 5'-CCTAACGCTATCTAGACATGGCGCGCCGGCTCTATACTAG-3' \\
\hline dT40 & | 5'-TTTTTTTTTTTTTTTTTTTTTTTTTTTTTTTTTTTTTTTT-3' \\
\hline $5 \mathrm{G} 1$ & 5'-GCGTGGTTCGCTCGGGATCCGAGTAGTACTATTCGG-3' \\
\hline $5 G 2$ & 5'-CTAACGCTATCTAGACATGGCGCGCCGGCTCTATACTAG-3' \\
\hline $10 \mathrm{G} 1$ & 5'-GCGTGGTTCGCTCGGGATCCGAGTAGTACTATTCG-3' \\
\hline $10 \mathrm{G} 2$ & 5'-CGCTATCTAGACATGGCGCGCCGGCTCTATACTAG-3' \\
\hline $20 G 1$ & 5'-GCGTGGTTCGCTCGGGATCCGAGTAGTACT-3' \\
\hline
\end{tabular}




\begin{tabular}{|l|l|}
\hline $20 G 2$ & 5'-TCTAGACATGGCGCGCCGGCTCTATACTAG-3' \\
\hline $40 G 1$ & 5'-GCGTGGTTCGCTCGGGATCC-3' \\
\hline $40 \mathrm{G} 2$ & 5'-GCGCGCCGGCTCTATACTAG-3' \\
\hline $80 \mathrm{dT}$ & $\begin{array}{l}\text { 5'-TTTTTTTTTTTTTTTTTTTTTTTTTTTTTTTTTTTTTTTT- } \\
\text { TTTTTTTTTTTTTTTTTTTTTTTTTTTTTTTTTTTTTTTT-3 }\end{array}$ \\
\hline
\end{tabular}

\begin{tabular}{|c|c|}
\hline Strain number & Genotype \\
\hline NHY7660 & NHY7576 X NHY7657 \\
\hline NHY10565 & NHY10559 X NHY10562 \\
\hline NHY10568 & NHY10561 X NHY10564 \\
\hline NHY11079 & NHY11075 X NHY11077 \\
\hline NHY11080 & NHY11076 X NHY11078 \\
\hline NHY7576 & 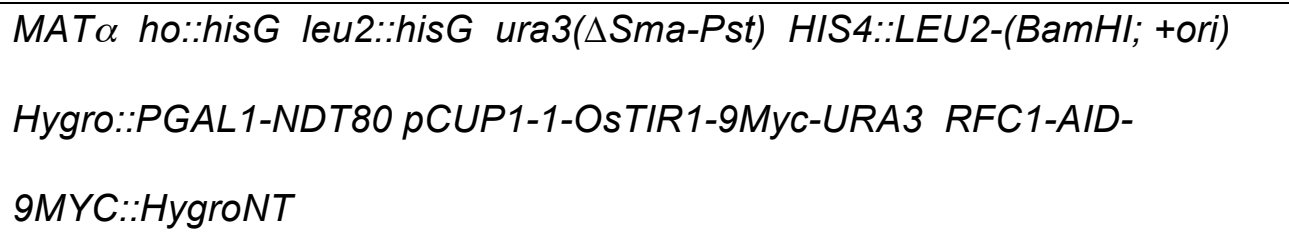 \\
\hline NHY7657 & $\begin{array}{l}\text { MATa ho::hisG leu2::hisG ura3(ASma-Pst) his4-X::LEU2-(NgoMIV; +ori)-- } \\
\text { URA3 Hygro::PGAL1-NDT80 ura3:PGPD1-GAL4(848)-ER:URA3 } \\
\text { Iys2::Hygro::pCUP1-1-OsTIR1-9myc RFC1-AID-9myc::HygroNT }\end{array}$ \\
\hline NHY10559 & $\begin{array}{l}\text { MATa ho::hisG leu2::hisG ura3(ASma-Pst) HIS4::LEU2-(BamHI; +ori) } \\
\text { Hygro::PGAL1-NDT80 pCUP1-1-OsTIR1-9Myc-URA3 RFC1-AID- } \\
\text { 9MYC::HygroNT MIh1-710-HA6-713::KanMX }\end{array}$ \\
\hline NHY10561 & 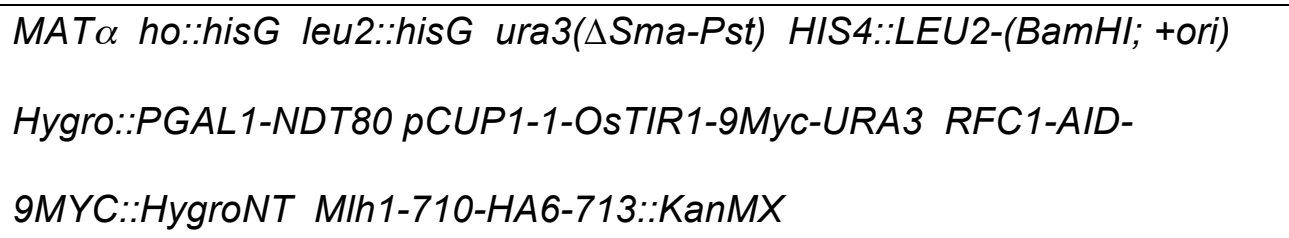 \\
\hline
\end{tabular}




\begin{tabular}{|c|c|}
\hline NHY10562 & $\begin{array}{l}\text { MAT } \alpha \text { ho::hisG leu2::hisG ura3(ASma-Pst) his4-X::LEU2-(NgoMIV; +ori)-- } \\
\text { URA3 Hygro::PGAL1-NDT80 ura3:PGPD1-GAL4(848)-ER:URA3 } \\
\text { lys2::Hygro::pCUP1-1-OsTIR1-9myc RFC1-AID-9myc::HygroNT MIh1-710- } \\
\text { HA6-713::KanMX }\end{array}$ \\
\hline NHY10564 & $\begin{array}{l}\text { MATa ho::hisG leu2::hisG ura3(ASma-Pst) his4-X::LEU2-(NgoMIV; +ori)-- } \\
\text { URA3 Hygro::PGAL1-NDT80 ura3:PGPD1-GAL4(848)-ER:URA3 } \\
\text { Iys2::Hygro::pCUP1-1-OsTIR1-9myc RFC1-AID-9myc::HygroNT MIh1-710- } \\
\text { HA6-713::KanMX }\end{array}$ \\
\hline NHY11075 & 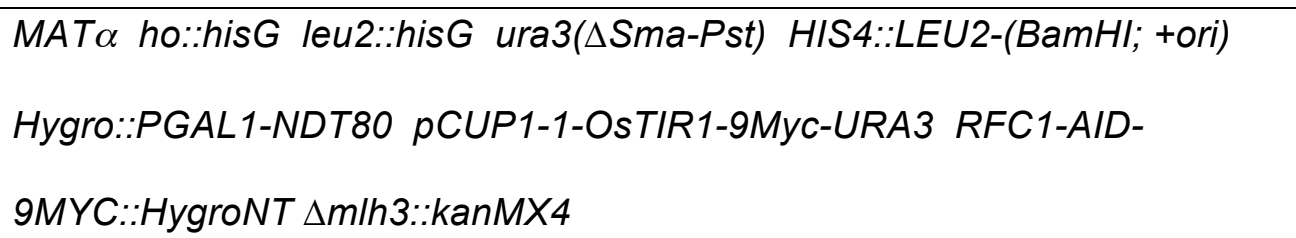 \\
\hline NHY11076 & 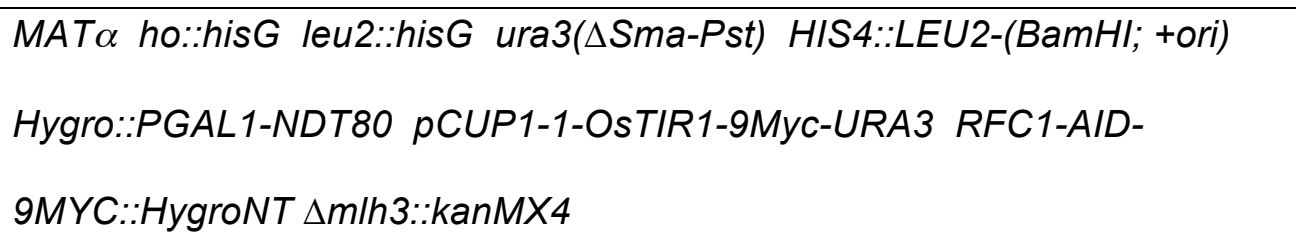 \\
\hline NHY11077 & $\begin{array}{l}\text { MATa ho::hisG leu2::hisG ura3(ASma-Pst) his4-X::LEU2-(NgoMIV; +ori)-- } \\
\text { URA3 Hygro::PGAL1-NDT80 ura3:PGPD1-GAL4(848)-ER:URA } \\
\text { Iys2::Hygro::pCUP1-1-OsTIR1-9myc RFC1-AID-9myc::HygroNT } \\
\text { AmIh3::kanMX4 }\end{array}$ \\
\hline NHY11078 & $\begin{array}{l}\text { MATa ho::hisG leu2::hisG ura3(ASma-Pst) his4-X::LEU2-(NgoMIV; +ori)-- } \\
\text { URA3 Hygro::PGAL1-NDT80 ura3:PGPD1-GAL4(848)-ER:URA } \\
\text { Iys2::Hygro::pCUP1-1-OsTIR1-9myc RFC1-AID-9myc::HygroNT } \\
\text { AmIh3::kanMX4 }\end{array}$ \\
\hline
\end{tabular}

